\title{
Neuronal hemoglobin affects dopaminergic cells' response to stress
}

\author{
Marta Codrich ${ }^{1,2}$, Maria Bertuzzi ${ }^{1}$, Roberta Russo ${ }^{1}$, Margherita Francescatto ${ }^{3}$, Stefano Espinoza ${ }^{3}$, Lorena Zentilin ${ }^{4}$, Mauro Giacca ${ }^{4}$, \\ Daniela Cesselli ${ }^{5}$, Antonio Paolo Beltrami ${ }^{5}$, Paolo Ascenzi ${ }^{6}$, Silvia Zucchelli ${ }^{1,2}$, Francesca Persichetti ${ }^{2}$, Giampiero Leanza ${ }^{7}$ and \\ Stefano Gustincich ${ }^{*, 1,3}$
}

Hemoglobin $(\mathrm{Hb})$ is the major protein in erythrocytes and carries oxygen $\left(\mathrm{O}_{2}\right)$ throughout the body. Recently, $\mathrm{Hb}$ has been found synthesized in atypical sites, including the brain. $\mathrm{Hb}$ is highly expressed in $\mathrm{A} 9$ dopaminergic (DA) neurons of the substantia nigra (SN), whose selective degeneration leads to Parkinson's disease (PD). Here we show that Hb confers DA cells' susceptibility to 1-methyl-4-phenylpyridinium (MPP ${ }^{+}$) and rotenone, neurochemical cellular models of PD. The toxic property of $\mathrm{Hb}$ does not depend on $\mathrm{O}_{2}$ binding and is associated with insoluble aggregate formation in the nucleolus. Neurochemical stress induces epigenetic modifications, nucleolar alterations and autophagy inhibition that depend on $\mathrm{Hb}$ expression. When adeno-associated viruses carrying $\alpha$ - and $\beta$-chains of $\mathrm{Hb}$ are stereotaxically injected into mouse $\mathrm{SN}, \mathrm{Hb}$ forms aggregates and causes motor learning impairment. These results position $\mathrm{Hb}$ as a potential player in DA cells' homeostasis and dysfunction in PD.

Cell Death and Disease (2017) 8, e2538; doi:10.1038/cddis.2016.458; published online 5 January 2017

Parkinson's disease (PD) is a chronic progressive neurodegenerative disorder clinically defined in terms of motor symptoms. The most evident pathological hallmarks are the selective degeneration of A9 dopaminergic (DA) neurons of substantia nigra pars compacta (SNpc) and the presence of intracellular aggregates called Lewy bodies. The consequent loss of DA synapses in the striatum is the primary origin of the inability to control movements. ${ }^{1}$ The causes of the selective degeneration of $A 9$ neurons remain unknown. ${ }^{2}$

The identification of genes involved in early-onset PD has proved the crucial role of mitochondria, ${ }^{1}$ of the ubiquitinproteasome system ${ }^{1}$ and autophagy. ${ }^{3}$

Epidemiological data showed that rural areas with heavy use of pesticides present a higher incidence of PD. ${ }^{4}$ The insecticide rotenone and the neurotoxin precursor 1-methyl-4phenyl-1,2,3,6-tetrahydropyridine (MPTP) have been extensively used as PD-mimicking models to study the molecular mechanisms of DA cells' degeneration. ${ }^{5,6}$ Both of them provoke depletion of intracellular ATP intervening on the homeostasis of mitochondrial activity and autophagy. ${ }^{7-9}$

In this context, the structure and function of the nucleolus have been found altered in post mortem PD brains. A correct ribosome biogenesis is essential to the survival of $D A$ neurons in vivo ${ }^{10}$ while nucleolar damage is present in mouse DA cells upon MPTP intoxication. ${ }^{11}$

In the quests for the molecular basis of DA cells' dysfunction in $\mathrm{PD}$, interesting cues have been obtained by comparing the molecular constituents of A9 DA cells of the $\mathrm{SN}$ with those of the adjacent A10 DA neurons of the ventral tegmental area. As these cells do not degenerate in PD, differential gene expression analysis has been associated with A9 susceptibility in disease. Examination of gene categories has highlighted that genes encoding energy-related metabolism, electron transport and mitochondria proteins appear to be more expressed in $\mathrm{A} 9$ rather than $\mathrm{A} 10$ neurons. ${ }^{2}$

We and others have previously identified the transcripts of $\alpha$ - and $\beta$-chains of hemoglobin $(\mathrm{Hb})$ in A9 DA neurons. ${ }^{12,13} \mathrm{Hb}$ immunoreactivity decorates the large majority of the nucleus and cytoplasm of A9 cells, whereas it stains only $<5 \%$ of $A 10$ neurons proving that $\mathrm{Hb}$ is differentially expressed in the DA cells' groups. In the mesencephalon, $\mathrm{Hb}$ retains its tetrameric structure as in blood. ${ }^{14}$

The function of $\mathrm{Hb}$ in $\mathrm{DA}$ neurons remains unclear. We have previously shown that its overexpression in a mouse DA cell line was altering transcript levels of genes involved in oxygen $\left(\mathrm{O}_{2}\right)$ homeostasis and oxidative phosphorylation. ${ }^{12}$

In this study, we provide evidence that neuronal $\mathrm{Hb}$ may contribute to DA cells' dysfunction in PD by interfering with pathways involved in neurodegeneration.

\section{Results}

$\mathrm{Hb}$ increases susceptibility to cell death in cellular models of PD. To investigate the role of $\mathrm{Hb}$ in PD, we analysed the effects of $\mathrm{Hb}$ overexpression upon

\footnotetext{
${ }^{1}$ Area of Neuroscience, Scuola Internazionale Superiore di Studi Avanzati (SISSA), via Bonomea 265, Trieste 34136, Italy; ${ }^{2}$ Department of Health Sciences, University of Eastern Piedmont 'A. Avogadro', via Solaroli 17, 28100 Novara, Italy; ${ }^{3}$ Department of Neuroscience and Brain Technologies, Istituto Italiano di Tecnologia (IIT), via Morego 30, Genova 16163, Italy; ${ }^{4}$ ICGEB, Padriciano 99, 34149 Trieste, Italy; ${ }^{5}$ Department of Medical and Biological Sciences, University of Udine, Piazzale Kolbe 4, Udine, 33100, Italy; ${ }^{6}$ Department of Sciences, University of Roma Tre, viale G. Marconi 446, Roma 00146, Italy and ${ }^{7}$ Department of Life Sciences, University of Trieste, via Fleming 22 , Trieste 34127, Italy

*Corresponding author: S Gustincich, Department of Neuroscience and Brain Technologies, Istituto Italiano di Tecnologia (IIT), via Morego 30, Genova 16163, Italy. Tel: +39 010 71781447; Fax: +39 010 71781230; E-mail: stefano.gustincich@iit.it or

Area of Neuroscience, Scuola Internazionale Superiore di Studi Avanzati (SISSA), via Bonomea 265, Trieste 34136, Italy. Tel: +39 0403787705 ; Fax: +39 040 3787702; E-mail: gustinci@ sissa.it

Received 29.8.16; revised 21.11.16; accepted 05.12.16; Edited by A Finazzi-Agro'
} 
PD-mimicking insults. We took advantage of the DA cell line iMN9D whose differentiation can be triggered by an inducible artificial system to increase the expression of Nurr1, a transcription factor involved in DA cells' differentiation and maintenance. These cells overexpress stably $\alpha$ - and $\beta$-chains of $\mathrm{Hb}$ forming the $a_{2} \beta_{2}$ tetramer. ${ }^{12,14}$

Differentiated cells were treated with increasing concentrations of 1-methyl-4-phenylpyridinium $\left(\mathrm{MPP}^{+}\right)$, the active ion of the neurotoxin MPTP, or of the pesticide rotenone. Both molecules induce mitochondrial dysfunction leading to caspase activation and cell death. ${ }^{1,8}$ Upon their administration, we analysed the levels of cleaved Caspase-3, a marker of apoptosis, through western blotting. We then tested cell mortality with FACS and monitored the metabolic activity of viable cells with WST-1.

First, we focussed our attention on differentiated cells treated with $\mathrm{MPP}^{+}$. Twenty-four hours after plating, doxycycline was supplemented to induce Nurr1 expression and DA cells' differentiation. $\mathrm{MPP}^{+}$was added $56 \mathrm{~h}$ later when cells were approximately $80 \%$ confluent. After additional $16 \mathrm{~h}$, cells were collected and analysed. We used $\mathrm{MPP}^{+}$at the concentrations of $0.1,0.2,0.5$ or $1 \mathrm{mM}$. Levels of cleaved Caspase- 3 were higher in $\mathrm{Hb}$ cells than controls in a dosedependent manner (Figure 1a). Densitometric quantification of pro-Caspase-3 and cleaved Caspase-3 are shown in Supplementary Figures S1a and c. FACS analysis demonstrated that cell death was more evident in $\mathrm{Hb}$ cells upon $1 \mathrm{mM}$ $\mathrm{MPP}^{+}$addition (Figure $1 \mathrm{~b}$ ). WST- 1 assay showed that $\mathrm{Hb}$ cells exhibited about $20 \%$ less viability in comparison to controls upon $\mathrm{MPP}^{+}$treatment (Figure 1c).

We then analysed the effects of rotenone in the same experimental settings. We used rotenone at the concentrations of $1,10,50$ or $100 \mu \mathrm{M}$. A higher level of cleaved Caspase-3 was evident in $\mathrm{Hb}$ cells when compared with controls upon rotenone treatment in a dose-dependent manner (Figure 1d). Densitometric quantification of proCaspase-3 and cleaved Caspase-3 are shown in Supplementary Figures S1b and d. FACS analysis showed a higher death ratio in $\mathrm{Hb}$ cells upon drug treatments (Figure 1e). WST-1 assay proved $\mathrm{Hb}$ cells presented about $30 \%$ less viability in comparison to controls upon rotenone administration (Figure 1f).

To assess whether $\mathrm{Hb}$ toxicity is $\mathrm{O}_{2}$ dependent, we generated a stable cell line overexpressing a mutant $\mathrm{Hb}$ (mut $\mathrm{Hb}$ ) that is unable to bind $\mathrm{O}_{2}$. In detail, we mutated the proximal histidine residue (F8) of both $\alpha$ - and $\beta$-chains to glycine. This small residue does not allow the fifth coordination bond of the heme-Fe atom. ${ }^{15,16}$ Once mutated, $\mathrm{Hb}$ cells were generated (Supplementary Figures S2a and b), differentiated and their mortality compared with $\mathrm{Hb}$ cells and controls upon PD-mimicking insults. As shown in Supplementary Figure $\mathrm{S} 2 \mathrm{c}$, mut $\mathrm{Hb}$ cells did not prevent $\mathrm{Hb}$ toxicity. Although there was slightly less cleaved Caspase- 3 in mut $\mathrm{Hb}$ cells in comparison to $\mathrm{Hb}$ cells, we interpreted it as owing to lower $\mathrm{Hb}$ level in mut $\mathrm{Hb}$ cells (Supplementary Figure S2a).

These experiments indicate that $\mathrm{Hb}$ overexpression increases susceptibility to cell death in cellular models of PD with mechanisms that do not depend on $\mathrm{O}_{2}$ binding.

Neurochemical intoxication increases $\mathrm{Hb}$ in the nucleus. We performed cellular fractionation experiments to study the intracellular distribution of $\mathrm{Hb}$ upon PD-mimicking insults. In untreated conditions, $\alpha$ - and $\beta$-chains were present both in

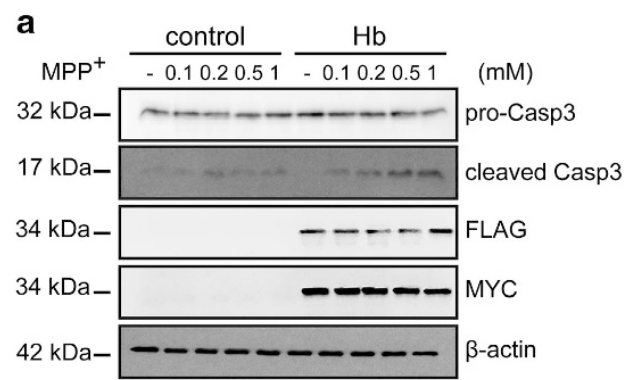

d

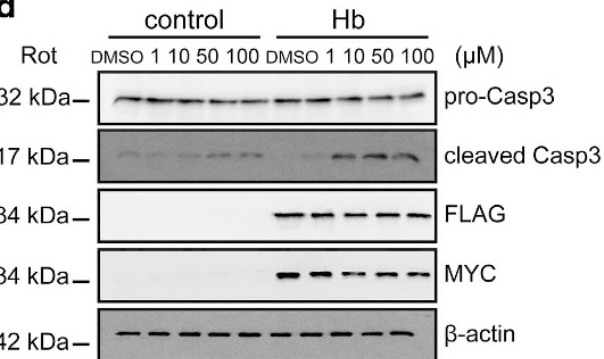

b
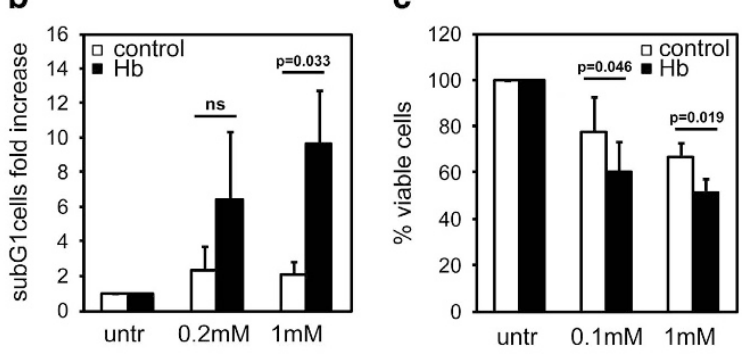

e

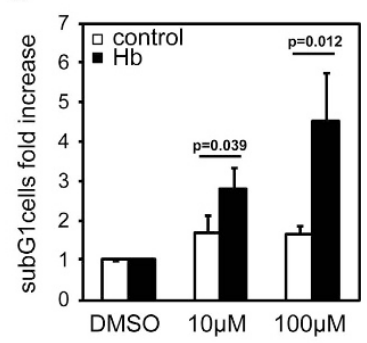

f

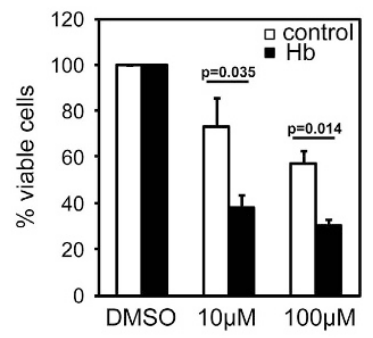

Figure $1 \mathrm{Hb}$ increases susceptibility to cell death in cellular model of PD. Differentiated $\mathrm{Hb}$ cells $(\mathrm{Hb})$ and control cells (control) were treated with MPP ${ }^{+}(\mathrm{a}-\mathrm{c})$ or rotenone $(\mathbf{d}-\mathbf{f})$ at the indicated concentrations for $16 \mathrm{~h}$. (a and $\mathbf{d}$ ) Western blotting analysis of cleaved Caspase-3 (cleaved Casp3) expression. $\alpha$ - and $\beta$-Globins were detected with antiFLAG and anti-MYC antibodies, respectively. For normalization, the levels of pro-Caspase-3 (pro-Casp3) were detected. $\beta$-Actin was used as a loading control. ( $n=3, n=3$ ) (b and e) FACS analysis. Percentage of subG1 cells is expressed as fold increased relative to untreated cells, arbitrary set to 1 . $(n=3, n=4)$ (c and f) WST-1 analysis. In graph are represented the percentage of viable cells relative to untreated cells, arbitrary set to $100 \%$. $(n=4, n=3)$ Values are mean \pm S.D. Data were evaluated statistically by Student's t-test. Resulting $P$-values are indicated (NS $=$ not significant) 
a

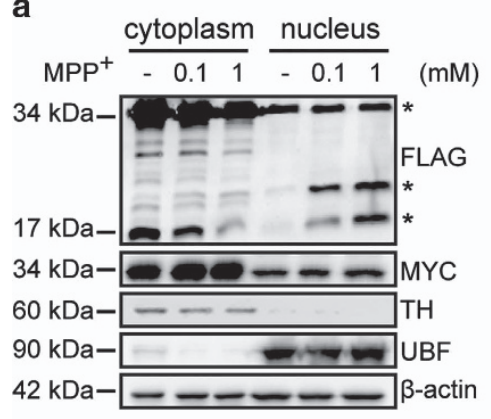

C

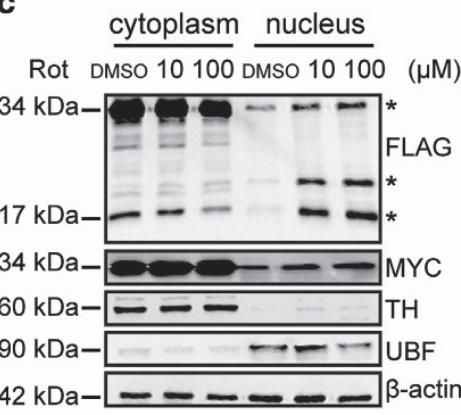

e

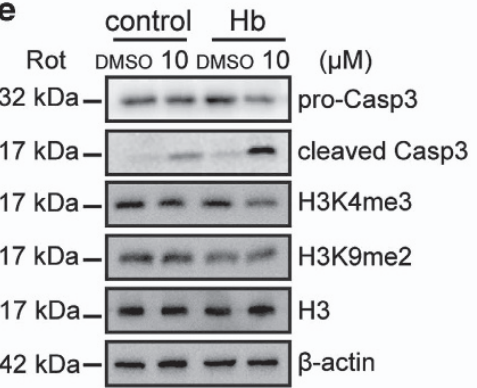

b
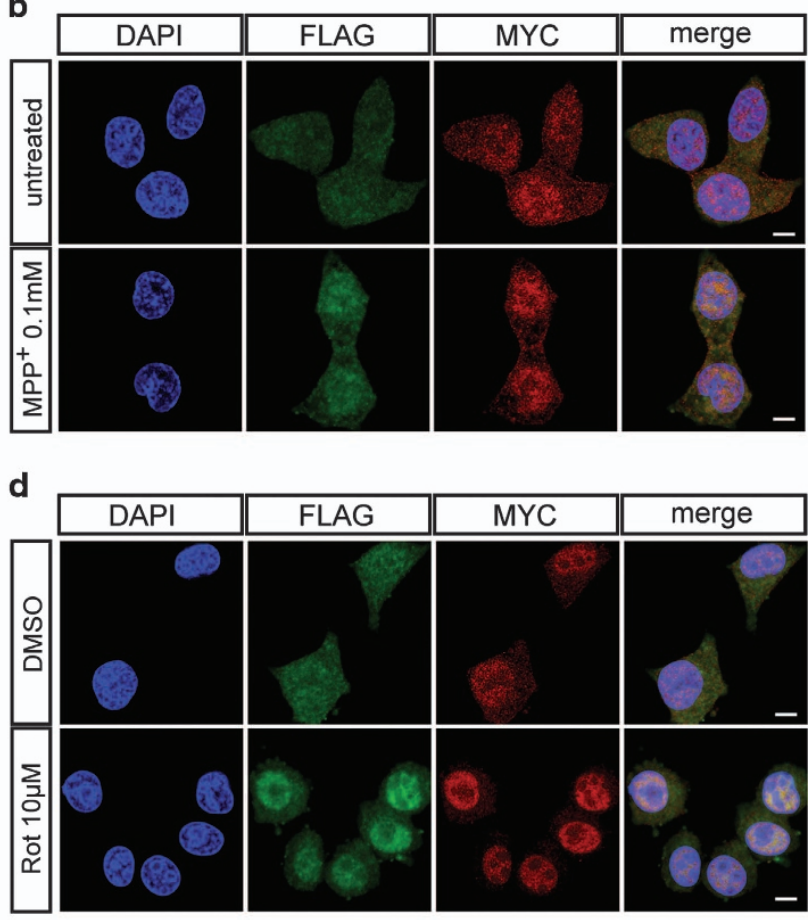

f
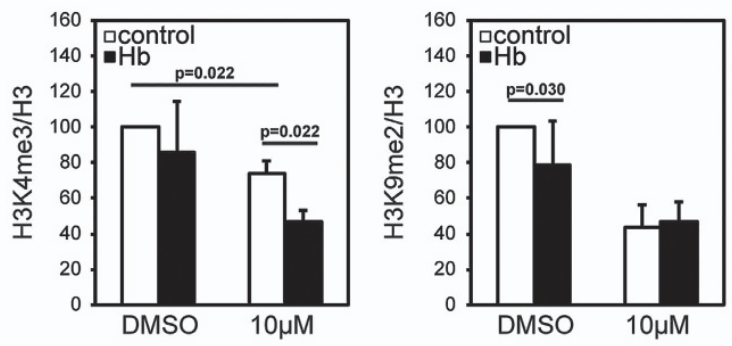

Figure 2 Neurochemical intoxication increases $\mathrm{Hb}$ in the nucleus. Differentiated $\mathrm{Hb}$ cells were treated with $\mathrm{MPP}^{+}(\mathbf{a}$ and $\mathbf{b})$ or rotenone (c-f) at the indicated concentrations for $16 \mathrm{~h}$. (a and $\mathbf{c}$ ) Western blotting analysis of cellular fractionation was carried out with anti-FLAG ( $\alpha$-globin) and anti-MYC ( $\beta$-globin) antibodies. Anti-TH and anti-UBF antibodies were used to visualize specifically cytoplasm and nucleus compartment, respectively. $\beta$-Actin was used as a loading control. $(n=5, n=4)(\mathbf{b}$ and $\mathbf{d})$ Double immunofluorescence was performed with anti-FLAG ( $\alpha$-globin) and anti-MYC ( $\beta$-globin) antibodies. Nuclei were marked by DAPI (4,6-diamidino-2-phenylindole). Scale bar $5 \mu$ m. $(n=3, n=4)$ (e) Western blotting analysis of H3K4me3 and H3K9me2 expression. For normalization, the total levels of $\mathrm{H} 3$ and $\beta$-actin were detected. Levels of pro-Caspase-3 (pro-Casp3) and cleaved Caspase-3 (cleaved Casp3) were also monitored. ( $n=3$ ) (f) Densitometric analysis of H3K4me3 and H3K9me2 expression. H3K4me3 and H3K9me2 levels were normalized to $\mathrm{H} 3$ and $\beta$-actin. Untreated control cells was used as reference and set to $100 \%$. $(n=3, n=3)$ Values are mean \pm S.D. Data were evaluated statistically by Student's $t$-test. The $P$-values were adjusted for multiple testing using the Benjamini-Hochberg method to control the false discovery rate. Resulting $P$-values are indicated

the cytoplasm and in the nucleus of differentiated iMN9Dcells (Figures $2 \mathrm{a}-\mathrm{d}$ ). Upon $\mathrm{MPP}^{+}$and rotenone treatments, the levels of $a$-globin (visualized with anti-FLAG antibody) and $\beta$ globin (visualized with anti-MYC antibody) increased in the nucleus (Figures 2a and c). Interestingly, an a-globin band of about $20 \mathrm{kDa}$ appeared in the nucleus, unveiling posttranslational modifications of the $a$-chain potentially associated with toxicity. Densitometric quantification of nuclear FLAG ( $a$ globin) and MYC ( $\beta$-globin) are shown in Supplementary Figures S1e-h. Mutated $a$-globin accumulated in the nucleus upon rotenone treatment as reported for wild-type $\mathrm{Hb}$, indicating again that $\mathrm{Hb}$-mediated toxic mechanisms do not require $\mathrm{O}_{2}$ binding (Supplementary Figure S2d). These results were confirmed with immunofluorescence (Figures $2 b$ and $\mathrm{d}$ ).
Importantly, $\alpha$ - and $\beta$-chains assembly was not altered upon toxic stimuli (Supplementary Figures S3a and b).

These data prove that in differentiated $\mathrm{Hb}$ cells the exposure to $\mathrm{MPP}^{+}$and rotenone increases the amount of $\mathrm{Hb}$ in the nucleus and the fraction of a nuclear $\mathrm{Hb}$ form modified at posttranslational level.

$\mathrm{Hb}$ modifies the epigenetic status of DA neurons under stress. As MPTP and rotenone have been previously shown to affect the epigenome of neurons, ${ }^{17,18}$ we analysed $\mathrm{H} 3$ methylation status in our experimental settings (Figure 2e). The level of $\mathrm{H} 3$ lysine 9 dimethylation (H3K9me2) was reduced in $\mathrm{Hb}$ cells in comparison to control cells in untreated conditions, while treated $\mathrm{Hb}$ cells presented $27 \%$ less $\mathrm{H} 3$ lysine 4 trimethylation ( $\mathrm{H} 3 \mathrm{~K} 4 \mathrm{me} 3)$ than controls (Figure $2 \mathrm{f})$. It 
is well known that the $\mathrm{H} 3 \mathrm{~K} 4 \mathrm{me} 3$ signature is correlated with transcription activation. ${ }^{19,20}$ Among the validated targets, high levels of $\mathrm{H} 3 \mathrm{~K} 4 \mathrm{me} 3$ at promoter and coding regions of the p53 gene are known to facilitate p53 transcription. ${ }^{21}$ By taking advantage of qRT-PCR analysis in $\mathrm{Hb}$ and control cells, a correlation was showed between H4K4me3 and p53 mRNA levels (Supplementary Figure S3c).
These data prove that $\mathrm{Hb}$ can regulate the epigenome of neurons upon stress and in untreated conditions.

Neurochemical intoxication accumulates insoluble $\mathrm{Hb}$ in the nucleolus. As the formation of insoluble aggregates is a hallmark of PD, we tested the solubility of $\mathrm{Hb}$ in our experimental preparation. Figures $3 a$ and $b$ shows that upon

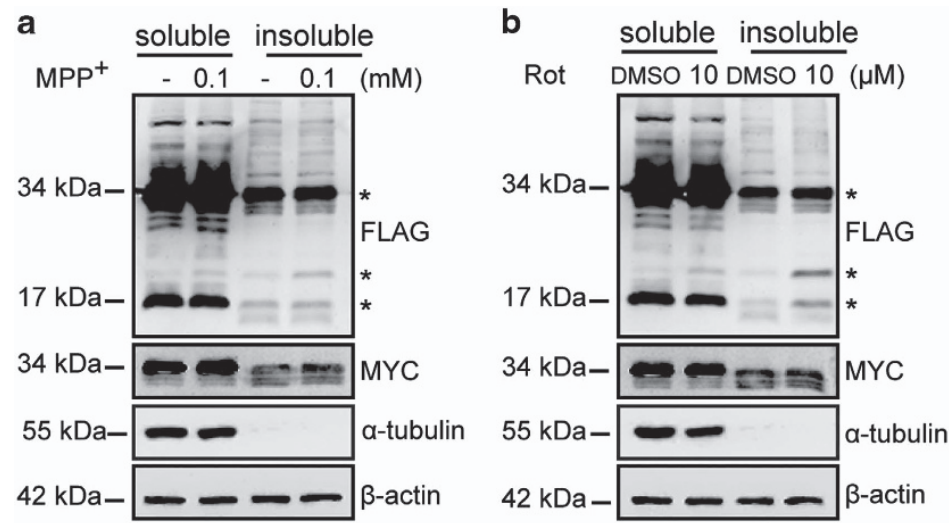

c $\square 34 \mathrm{kDa} \quad \square 20 \mathrm{kDa} \quad-17 \mathrm{kDa}$
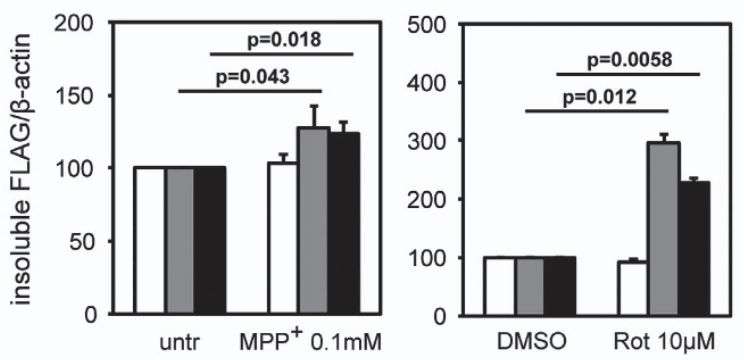

d

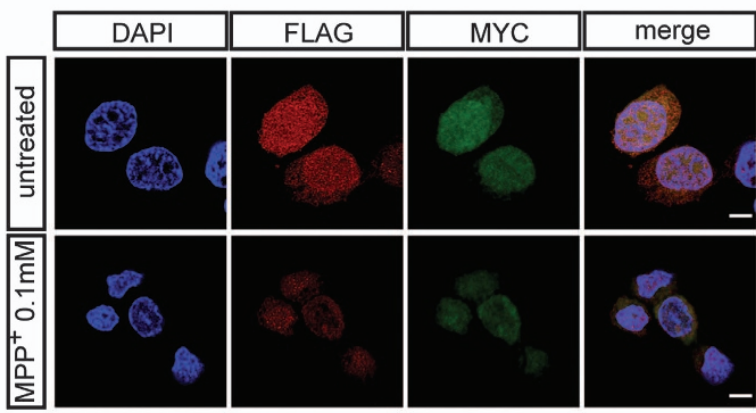

f

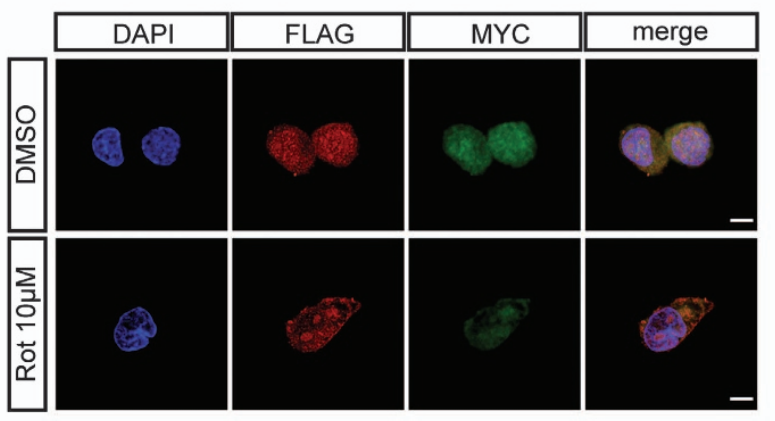

h

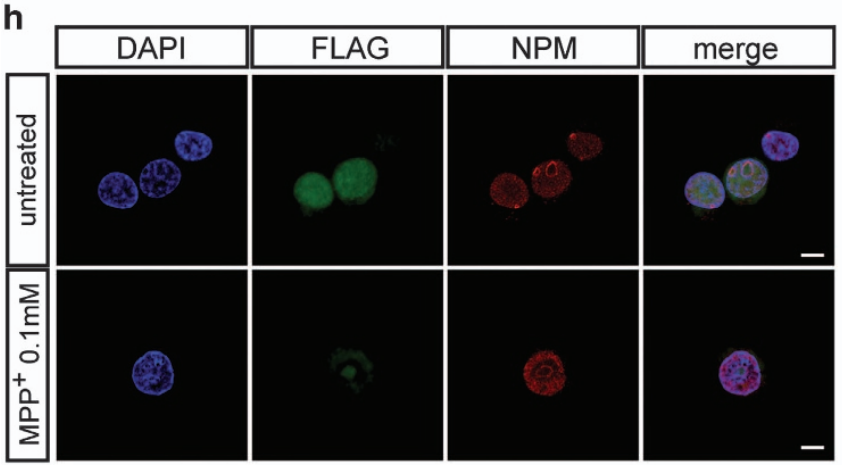

e

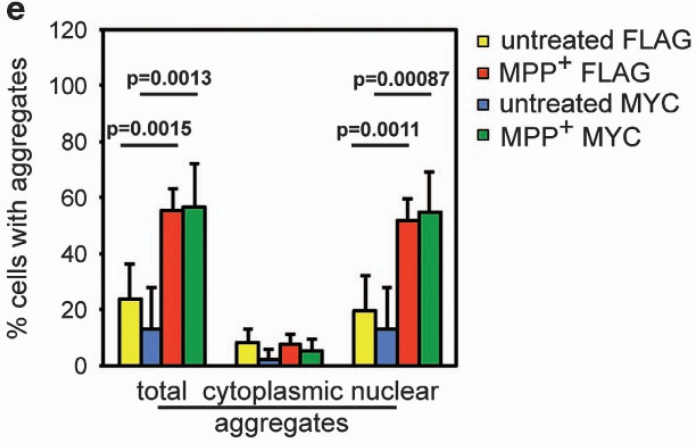

g
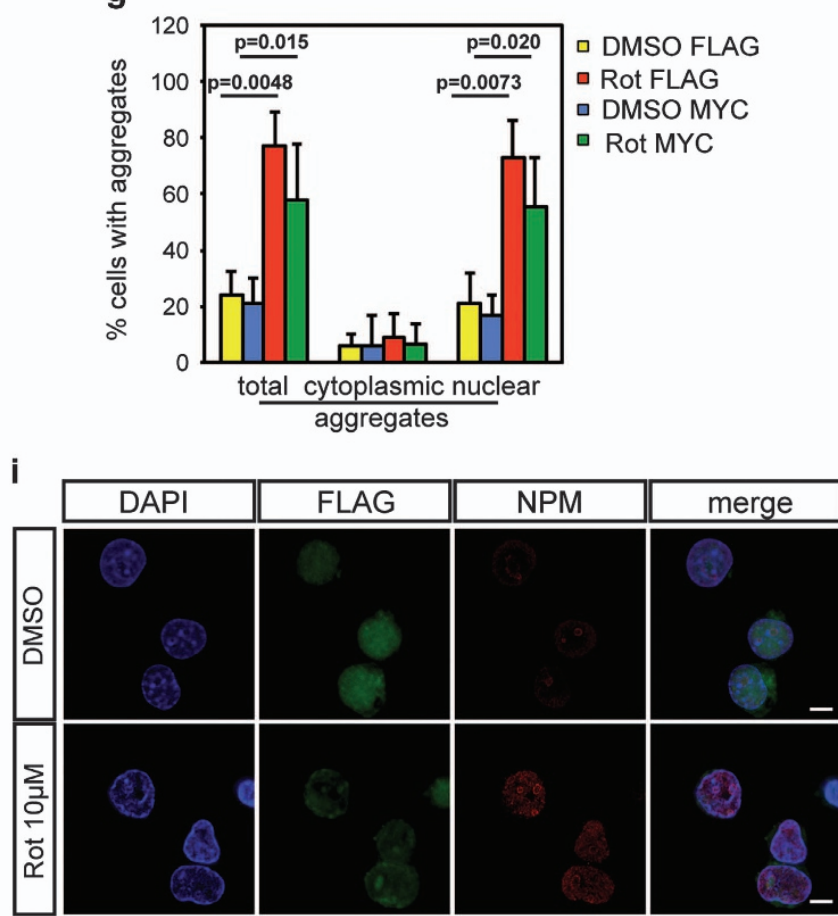
treatments with $\mathrm{MPP}^{+}$and rotenone $a$-chain accumulated in the insoluble portion while in untreated conditions globin chains were mainly, but not exclusively, localized in Triton $X-100$ soluble fractions. Furthermore, the quantification analysis of insoluble FLAG (a-globin)-positive bands demonstrates that there is an increase of the 17 and $20 \mathrm{kDa}$ bands upon treatments (Figure $3 \mathrm{c}$ ). Immunofluorescence analysis was then carried out after permeabilization with Triton X-100 before fixation. Although a small amount of $\alpha$ - and $\beta$-globincontaining aggregates were already present in untreated cells, PD-mimicking insults strongly induced $\mathrm{Hb}$ aggregation (Figures $3 d$ and f) mainly in the nucleus. The quantification of $\mathrm{Hb}$ insoluble aggregates are shown in Figures $3 \mathrm{e}$ and $\mathrm{g}$.

Double immunofluorescence for $a$-globins (visualized with anti-FLAG antibody) and Nucleophosmin (NPM), a specific marker for granular component of the nucleolus, proved that $\mathrm{Hb}$ aggregates were contained within nucleolar structures (Figures $3 \mathrm{~h}$ and i).

These data demonstrate that PD-mimicking insults increase nucleolar aggregation of $\mathrm{Hb}$.

$\mathrm{Hb}$ induces nucleolar stress. Given the presence of $\mathrm{Hb}$ aggregates in the nucleoli, we assessed the synthesis of prerRNA transcripts as a marker of nucleolar stress. Figure $4 a$ shows that $\mathrm{Hb}$ overexpression inhibited rRNA biogenesis in untreated cells. Importantly, PD-mimicking insult decreased pre-rRNA transcripts levels both in $\mathrm{Hb}$ cells and controls although with a statistically significant stronger effect on $\mathrm{Hb}$ cells.

These data indicate that $\mathrm{Hb}$ overexpression increases nucleolar stress affecting rRNA biosynthesis.

Hb impairs autophagy induced by neurochemical insults. Autophagy is a crucial homeostatic response of DA cells to neurochemical intoxication and its pharmacological induction with rapamycin protects cellular and animal models of $\mathrm{PD} .^{8,9}$ To investigate the effects of $\mathrm{Hb}$ overexpression, we monitored the phosphorylation status of the eukaryotic initiation factor $4 \mathrm{E}$ binding protein 1 (4E-BP1), a direct target of $\mathrm{mTOR}^{22}$ showing that in $\mathrm{Hb}$ cells the phosphorylation of 4E-BP1 was stable while reduced in control cells, as expected (Figure 4b).

These results indicate that $\mathrm{Hb}$ expression inhibits downregulation of $\mathrm{mTOR}$ activity by rotenone treatment. Densitometric quantification of P-4EB-P1 is shown in Supplementary Figure S1I.

We then monitored the induction of LC3II as a marker of autophagosome formation and therefore of autophagic activity. Although rotenone treatment triggered increased levels of
LC3II in control cells, in $\mathrm{Hb}$ cells it failed to do so (Figure 4b). Densitometric quantification of LC3II is shown in Supplementary Figure S1m. To further assess the impact of $\mathrm{Hb}$ on autophagy, neurons were stained with LysoTracker Red (Figure 4c), which labels acidic organelles, including autophagosomes in living cells. Upon rotenone treatment, the quantification of LysoTracker Red-positive foci per cell demonstrated in $\mathrm{Hb}$ cells the inhibition of the prominent rise of autophagosome density observed in controls (Figure 4d).

These data demonstrate that $\mathrm{Hb}$ overexpression is associated with an impairment of autophagy induction by preserving mTOR activity.

\section{AAV9-mediated delivery of $\mathrm{Hb}$ in SNpc inhibits improve- ment of motor performance and triggers $\mathrm{Hb}$ aggregates} in DA cells. To assess the role of $\mathrm{Hb}$ in DA neurons in vivo, we overexpressed $\mathrm{Hb}$ in SNpc of mouse brain. Eight-weekold male $\mathrm{C} 57 \mathrm{BI} / 6$ mice were injected with a mixture of AAV92xFLAG- $\alpha$-globin and AAV9- $\beta$-globin-MYC (indicated as AAV9-Hb) or with AAV9-control into SNpc of mouse brain. The contralateral SNpc remained uninjected. Supplementary Figure S4 shows the characterization of AAV9 vector injection in SNpc of mouse brain. Double immunofluorescence for $\mathrm{Hb}$ and the specific DA marker tyrosine hydroxylase $(\mathrm{TH})$ revealed that $\mathrm{AAV} 9$ vectors were efficiently transduced in DA neurons in the ipsilateral side (Supplementary Figures S4d and e). Furthermore, double immunofluorescence for tagged $\alpha$ - and $\beta$-globin demonstrated their co-localization in DA cells, confirming the efficiency of co-infection (Supplementary Figure S4g).

To determine $\mathrm{Hb}$ overexpression effects on DA neurons, we monitored mice motor coordination using rotarod test. We assayed AAV9-Hb and AAV9-control mice at the indicated weeks (Figure 5a). Data in Figure 5b show the mice latency, defined as the amount of time the mice stayed on the rotating rod at different r.p.m. No differences were observed in performance between AAV9-Hb and AAV9-control mice at all four speeds before AAV9 vector injection. During the time of the experiment, there was no group difference in performance at 5 and 10 r.p.m. Strikingly, when the difficulty of the test was increased (15 r.p.m.) we observed a statistical difference between AAV9-Hb- and AAV9-control-injected mice unveiling changes in locomotor activity that increased with time: AAV9-Hb (I) $123 \pm 25$, (II) $91 \pm 18$, (III) $112 \pm 20$; AAV9control (I) $148 \pm 21$, (II) $157 \pm 22$, (III) $200 \pm 23$. Although AAV9-control mice improved their performance, AAV9-Hb mice failed to do so. Finally, both groups had an unsuitable performance at 20 r.p.m.

Figure 3 Neurochemical intoxication accumulates insoluble $\mathrm{Hb}$ in the nucleolus. Differentiated $\mathrm{Hb}$ cells were treated with $\mathrm{MPP}^{+}(\mathbf{a}, \mathbf{d}, \mathbf{h})$ or rotenone $(\mathbf{b}, \mathbf{f}, \mathbf{i})$ at the indicated concentrations for $16 \mathrm{~h}$. (a and b) Western blotting analysis of soluble and insoluble fractionation was carried out with anti-FLAG ( $\alpha$-globin) and anti-MYC ( $\beta$-globin) antibodies. $\alpha$ Tubulin was used to visualize specifically soluble fraction. $\beta$-Actin was used as a loading control. (FLAG $n=3$, MYC $n=2 ;$ FLAG $n=4$, MYC $n=2$ ) (c) Densitometric analysis of insoluble FLAG ( $\alpha$-globin) level. Insoluble $\alpha$-globin level was normalized to $\beta$-actin. Untreated cells was used as reference and set to $100 \%$. ( $n=3, n=3$ ) (d and f) Solubilized double immunofluorescence was performed with anti-FLAG ( $\alpha$-globin) and anti-MYC ( $\beta$-globin) antibodies. Nuclei were marked by DAPI (4,6-diamidino-2-phenylindole). Scale bar $5 \mu \mathrm{m} .(n=3, n=3)$ (e and $\mathbf{g})$ Quantification of globin chain aggregates in the cells. An average of 120 randomly chosen cells were counted for quantification of each condition. Values are expresses as a percentage relative to the total. ( $h$ and i) Solubilized double immunofluorescence was performed with anti-FLAG ( $\alpha$-globin) and anti-NPM antibodies. Nuclei were marked by DAPI. Scale bar $5 \mu \mathrm{m} .(n=2, n=2)$ Values are mean \pm S.D. Data were evaluated statistically by Student's $t$-test. Resulting $P$-values are indicated 


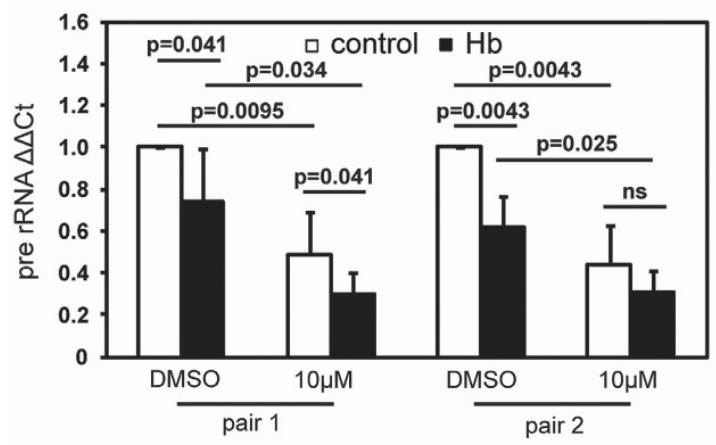

b

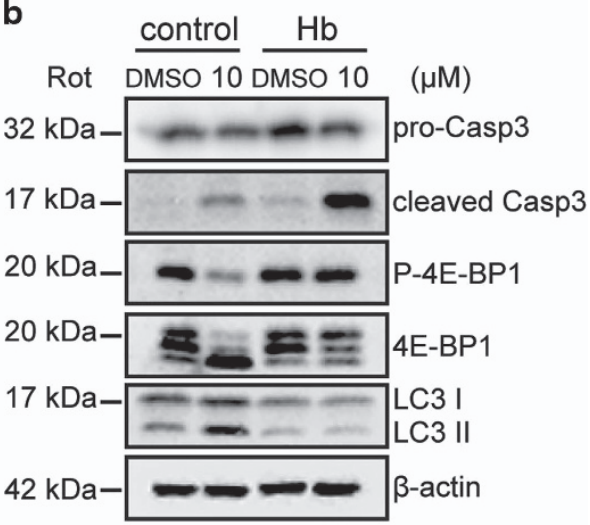

C

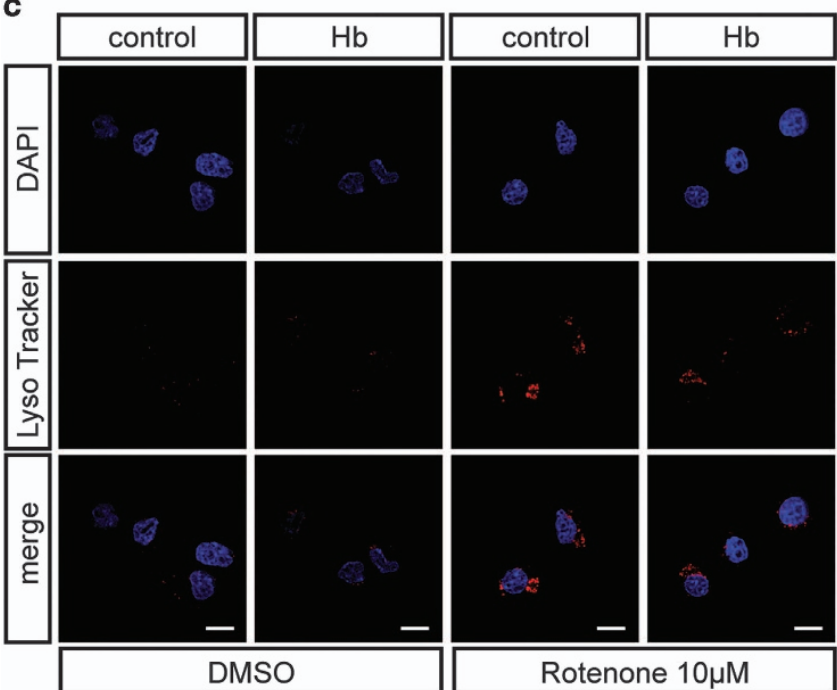

d

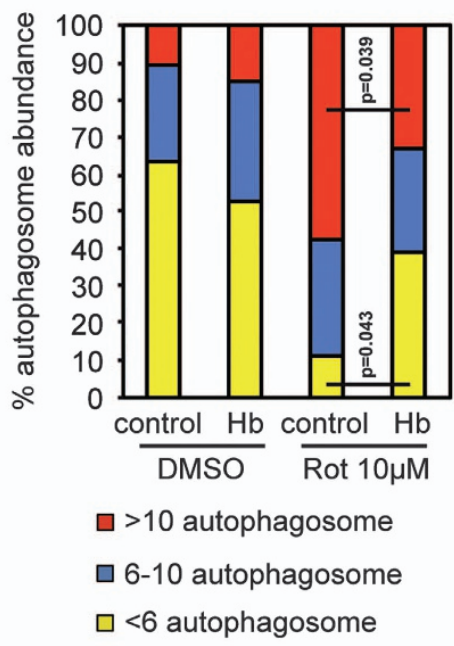

Figure $4 \mathrm{Hb}$ induces nucleolar stress and impairs autophagy in cellular model of PD. Differentiated $\mathrm{Hb}$ cells $(\mathrm{Hb})$ and control cells (control) were treated with rotenone at the indicated concentrations for $16 \mathrm{~h}$. (a) qRT-PCR of pre-rRNA levels. Pre-rRNA levels were normalized to $\beta$-actin. Untreated control cells was used as reference and set to 1 . ( $n=5$ ) (b) Western blotting analysis of phosphorylated 4E-BP1 (P-4E-BP1) status and LC3 expression. For normalization, the total levels of 4E-BP1 were detected. Levels of proCaspase-3 (pro-Casp3) and cleaved Caspase-3 (cleaved Casp3) were also monitored. $\beta$-Actin was used as a loading control. $(n=5)$ (c) LysoTracker Red staining. Nuclei were marked by DAPI (4,6-diamidino-2-phenylindole). Scale bar $10 \mu \mathrm{m}$. $(n=3)$ (d) Quantification of autophagosome. Ninety randomly chosen cells were counted for quantification of each condition. Values are expressed as a percentage relative to the total. Autophagy activity was defined as follows: high: >10 LysoTracker Red foci/cell; medium: 6-10 LysoTracker Red foci/cell; low: $<6$ LysoTracker Red foci/cell. Values are mean \pm S.D. Data were evaluated statistically by Student's $t$-test. The $P$-values were adjusted for multiple testing using the Benjamini-Hochberg method to control the false discovery rate. Resulting $P$-values are indicated (NS = not significant)

These data demonstrate that AAV9-mediated Hb expression in SNpc inhibits improvement in performance associated with motor learning. Recent evidence suggests that DA neurotrasmission is linked to cognitive function, in particular DA depletion impairs motor learning. ${ }^{23}$ Consequently, we performed HPLC on differentiated $\mathrm{Hb}$ and control cells to measure DA content. As shown in Supplementary Figure S5, DA level is significantly reduced by about $50 \%$ in $\mathrm{Hb}$ cells in comparison to controls.

Four weeks after AAV9 vector injection, mice were killed and brain tissues were processed for immunohistochemical analysis. We first performed a densitometric analysis of $\mathrm{TH}^{+}$ fibres in the striatum, direct target of DA innervation from the $\mathrm{SN}$. We observed that $\mathrm{Hb}$ overexpression did not alter $\mathrm{TH}^{+}$ fibres comparing AAV9-Hb and AAV9-control mice (Figures $5 \mathrm{c}$ and e). We then quantified DA neurons counting A9 cells in $\mathrm{SNpc}$ with a computer-assisted stereological assessment tool.
We first proved that the injection itself did not cause damage, as the number of $\mathrm{TH}^{+}$cells in the ipsilateral and contralateral sides of AAV9-control mice were equal (Figures $5 \mathrm{~d}$ and $\mathrm{f}$ ). We then showed that the total number of DA neurons was not altered by $\mathrm{Hb}$ overexpression. Interestingly, $\mathrm{Hb}$-overexpressing $\mathrm{TH}^{+}$cells presented cytoplasmic and nuclear a-globin aggregates (Figure $5 \mathrm{~g}$ ). The majority of these structures were immunoreactive for both tagged-globin proteins (Figure $5 \mathrm{~h}$ ).

These data suggest that $\mathrm{Hb}$ overexpression does not alter DA cells' anatomy but triggers aggregate formation in $\mathrm{TH}^{+}$ neurons.

\section{Discussion}

Globins are present in all kingdoms of living organisms where they display a variety of functions, including $\mathrm{O}_{2}$ sensing, 
a

\begin{tabular}{|c|c|c|c|c|c|}
\hline $\begin{array}{c}\text { Rota Rod } \\
\text { training }\end{array}$ & $\begin{array}{c}\text { Rota Rod } \\
\text { test (I) }\end{array}$ & $\begin{array}{c}\text { AAVs vector } \\
\text { surgery }\end{array}$ & $\begin{array}{c}\text { Rota Rod } \\
\text { test (II) }\end{array}$ & $\begin{array}{c}\text { Rota Rod } \\
\text { test (III) }\end{array}$ & \begin{tabular}{|c|} 
post-mortem \\
analysis
\end{tabular} \\
\hline 0 & & 2 & & & 7 \\
\hline
\end{tabular}

b
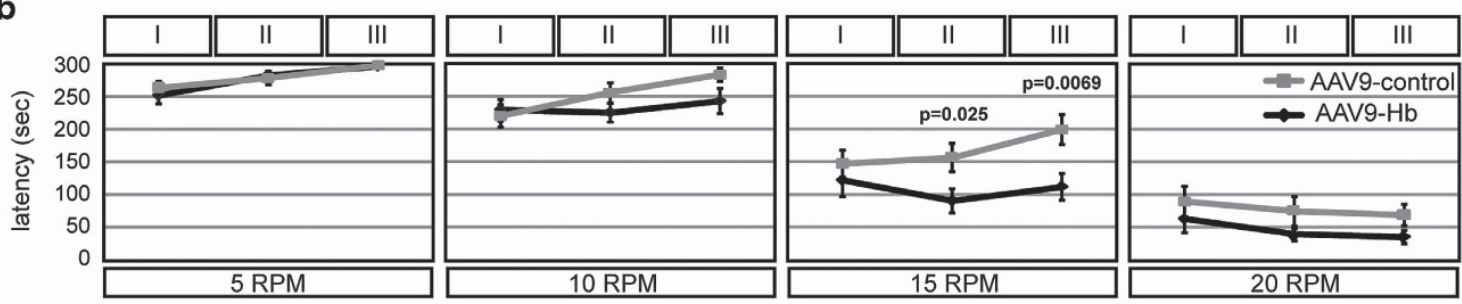

c
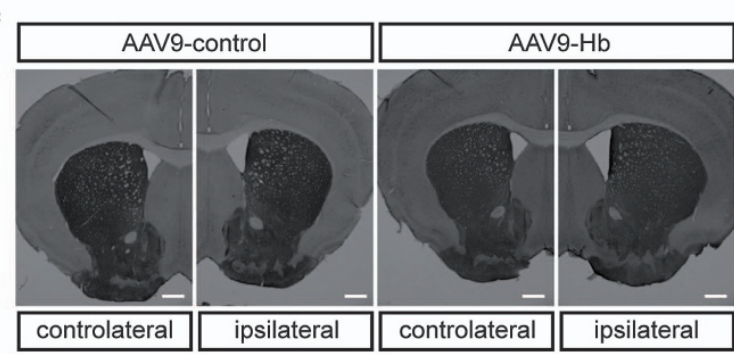

d
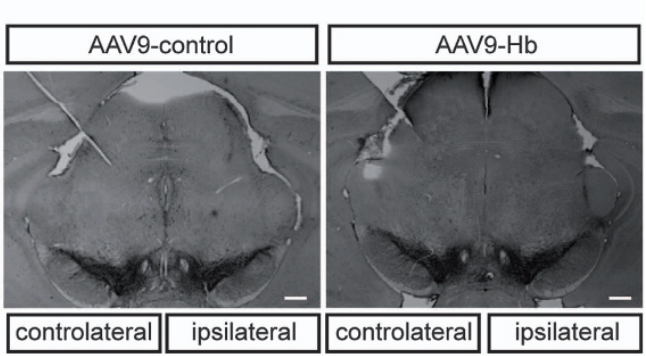

e

\section{f}
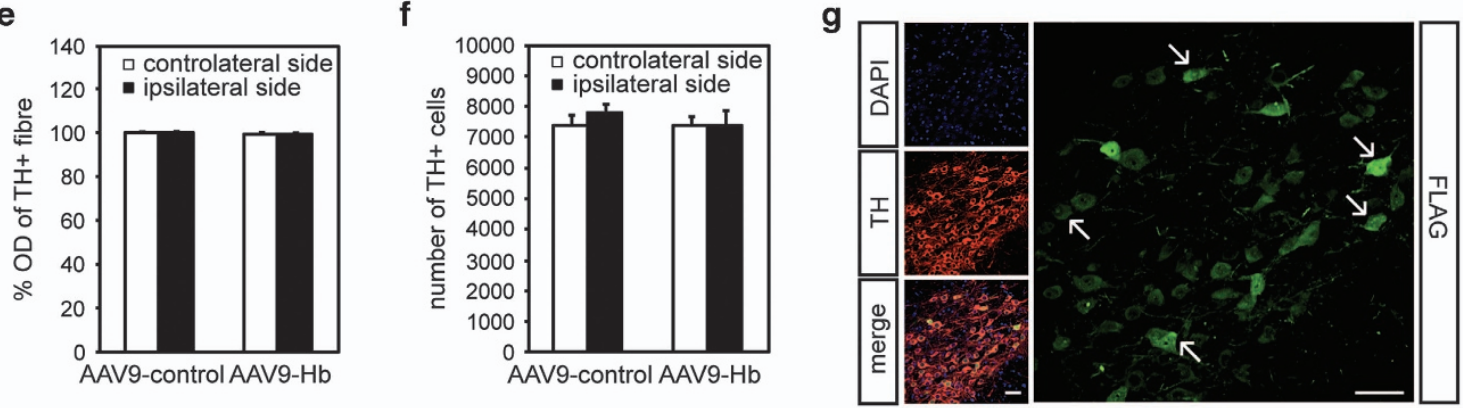

h

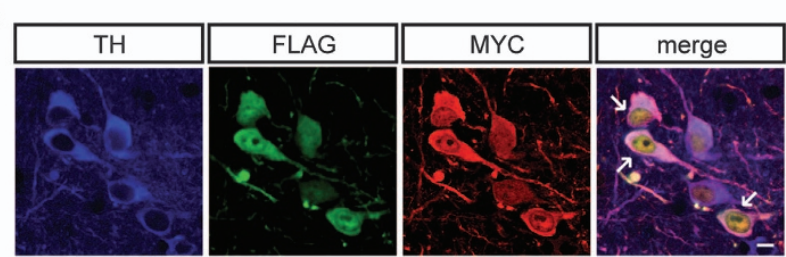

Figure 5 AAV9-mediated delivery of $\mathrm{Hb}$ in SNpc inhibits improvement of motor performance and triggers $\mathrm{Hb}$ aggregates in DA cells. (a) Scheme of experimental settings. (b) Latency in rotarod test in AAV9-control $(n=18)$ and AAV9-Hb $(n=19)$ mice at 5, 10, 15 and 20 r.p.m. (c) Immunohistochemistry of coronal sections of AAV9-control and AAV9- $\mathrm{Hb}$ mouse brain. $\mathrm{TH}^{+}$fibres in the striatum were stained with anti-TH antibody. Scale bar $800 \mu \mathrm{m}$. (d) Immunohistochemistry of coronal sections of AAV9-Hb and AAV9-control mouse brain. SN was stained with anti-TH antibody. Scale bar $200 \mu \mathrm{m}$. (e) Densitometric analysis of TH ${ }^{+}$fibres in AAV9-Hb $(n=18)$ and AAV9-control $(n=18)$ mice. Values are expresses as a percentage relative to the contralateral side of AAV9-control mice, arbitrary set to $100 \%$. (f) Quantitative analysis of $\mathrm{TH}^{+}$cells number in $\mathrm{AAV} 9-\mathrm{Hb}$ $(n=16)$ and AAV9-control $(n=15)$ mice. Values are expressed as the number of total $\mathrm{TH}^{+}$cells relative to the contralateral side of AAV9-control mice. (g) Immunohistochemistry of coronal sections of AAV9-Hb mouse brain. SN was stained with anti-TH antibody. Infected cells were stained with anti-FLAG ( $\alpha$-globin) antibody. Arrow indicates $\alpha$-globin aggregates. Nuclei were visualized with DAPI (4,6-diamidino-2-phenylindole). Scale bar $50 \mu \mathrm{m}$. (h) Immunohistochemistry of coronal sections of AAV9-Hb mouse brain. SN was stained with anti-TH antibody. Infected cells were stained with anti-FLAG ( $\alpha$-globin) and anti-MYC ( $\beta$-globin) antibodies. Arrow indicates globin aggregates. Scale bar $10 \mu$ m. All data are represented as mean \pm S.E.M. Data were evaluated statistically by one-way analysis of variance. Resulting $P$-values are indicated

transport and storage, the synthesis and scavenging of reactive nitrogen and oxygen species and heme-based catalysis. ${ }^{24}$ In the past decade, $\mathrm{Hb} \alpha$ - and $\beta$-chains have been found expressed in a plethora of nonerythroid cells. ${ }^{24}$

Several reports have shown regulated expression of $a$ - and $\beta$-chain transcripts as well as $\mathrm{Hb}$ immunoreactivity in the mammalian brain, including in neurons of the mesencephalon, cortex (CTX) and hippocampus ${ }^{13,25-27}$ as well as in oligodendrocytes and selective astrocytes. ${ }^{12,28}$

Recent evidences suggest the involvement of $\mathrm{Hb}$ in neurodegenerative diseases. First, an increase of $\mathrm{Hb}$ expression has been observed in neurons of aging brains in rodents 
and human. ${ }^{29,30} \mathrm{Hb}$ was found highly expressed in the neurons and glia in Alzheimer's disease (AD) brains, in APP/ $P S 1$ transgenic $A D$ mice models and in the cerebrospinal fluid of $\mathrm{AD}$ patients. ${ }^{30} \mathrm{Hb}$ co-localized with senile plaques and vascular amyloid deposits in AD while $\alpha$ - and $\beta$-chains were shown to interact with $A \beta$ oligomer in $A D$ brain homogenates promoting $A \beta$ oligomer formation. ${ }^{30}$ These results have led to the intriguing hypothesis that $\mathrm{Hb}$ may have an important role in the association between cerebral vascular diseases and AD. ${ }^{31}$

Transcriptome profiling showed that $\alpha$ - and $\beta$-globins were the two most induced transcripts in the white matter of patients suffering from multiple system atrophy. ${ }^{32}$ By contrast, they were the two most downregulated transcripts in the brains from bovine spongiform encephalopathy-infected cynomolgus macaques, a model for human prion disorders. ${ }^{33}$

Several intriguing observations suggest $\mathrm{Hb}$ as a potential player in PD. ${ }^{34}$ Its distribution in mesencephalic DA neurons enlists $\mathrm{Hb}$ into the small number of genes whose expression correlates with cells' vulnerability. ${ }^{2,12} \alpha$ - and $\beta$-Chains mRNAs were found strongly downregulated in DA neurons of rats treated with low doses of rotenone. ${ }^{35}$ Intriguingly, they were upregulated in post mortem PD brains. ${ }^{36}$ Furthermore, $\mathrm{Hb}$ and $a$-synuclein complex was recently found in brain tissue and red blood cells of aging cynomolgus monkeys. ${ }^{37}$

We previously showed that overexpression of $a$ - and $\beta$-chains in iMN9D cells altered the expression of genes involved in mitochondrial activity. ${ }^{12}$ Since then, $\mathrm{Hb}$ has been found accumulated in the mitochondria of human SN neurons and frontal CTX cells from post mortem PD brains. ${ }^{38,39}$ Here we have demonstrated that $\mathrm{Hb}$ overexpression increases susceptibility to cell death in differentiated iMN9D cells exposed to $\mathrm{MPP}^{+}$and rotenone. Both drugs are known to inhibit complex I of the mitochondrial electron transport chain provoking a decrease of the ATP reserve. ${ }^{7}$ Interestingly, $\mathrm{Hb}$ accumulates in the mitochondria of post mortem brain tissues of other diseases such as multiple sclerosis (MS), where it interacts with several mitochondrial proteins, including ATP synthase subunits. ${ }^{40}$

In this context, here we show for the first time that $\mathrm{Hb}$ is able to interfere with pathways crucial to PD pathogenesis such as DA content, nucleolar function, autophagy and epigenetic remodelling. Importantly, $\mathrm{Hb}$ forms insoluble aggregates in $\mathrm{DA}$ neurons in vitro and in vivo. Although the majority of these phenotypes are already present in untreated cells, they are strongly induced upon neurochemical intoxication.

The formation of detergent-insoluble aggregates is considered one of the hallmarks of $\mathrm{PD}$. $\mathrm{Hb}$ aggregates are induced by neurochemical intoxication in vitro and they accumulate upon $\alpha$ - and $\beta$-chain overexpression in DA neurons of the $\mathrm{SN}$ in vivo. Aggregates are formed prevalently in the nucleolus and are associated with a posttranslational modification of the $a$-chain present in the insoluble fraction. Further work is needed to assess its identity and role in $\mathrm{Hb}$ toxicity.

$\mathrm{Hb}$ aggregates are localized in the nucleoli in vitro. The main function of the nucleolus is to coordinate ribosome biogenesis although it is increasingly evident that it acts as a response centre to various insults, including oxidative and proteotoxic stresses. ${ }^{41}$ Nucleoli have been found essential to the survival of DA neurons in vivo ${ }^{11}$ while their structure and function are altered in post mortem PD brains. ${ }^{42,43}$ Interestingly, neurotoxic stimuli inhibited rRNA synthesis and impaired rRNA biogenesis. ${ }^{11}$ In this study, we show that $\mathrm{Hb}$ overexpression decreases pre-rRNA transcription inducing nucleolar stress upon intoxication and in untreated conditions. Although in the short-term this is considered a defence mechanism to limit energy squander preserving cell survival, protracted downregulation of rRNA transcription results in severe cellular damage and cell death. ${ }^{44}$ In this context, it has been recently demonstrated that the ablation of the RNA polymerase I-specific transcription initiation factor IA causes disruption of nucleoli and a transient pro-survival response, involving the inhibition of mTOR signaling and the activation of autophagy. ${ }^{45}$

Dysregulation of the autophagic pathway has been observed in human post mortem PD brains and in animal models while genes mutated in familial PD are involved in its regulation. ${ }^{46}$ Importantly, autophagy enhanced by rapamycin protects against cell death caused by MPTP and rotenone.8,47 An intriguing relationship may thus be hypothesized between $\mathrm{Hb}$ toxicity and its ability to inhibit mTOR impairing autophagy.

The role of epigenetics in PD is under intense scrutiny. Dopamine depletion is associated with a reduction in histone H3K4me3, whereas treatment with MPTP and rotenone induces $\mathrm{H} 3$ acetylation. ${ }^{18,48}$ The expression of epigenetic modifiers is dysregulated in the blood of living PD patients. ${ }^{18}$ Interestingly, $\beta$-globin interacts with $\mathrm{H} 3$ and histone lysine demethylase in post mortem MS CTX, ${ }^{40}$ suggesting that it may regulate $\mathrm{H} 3$ methylation status. It is therefore intriguing that upon PD-mimicking insults we observed an increase of $\mathrm{Hb}$ in the nucleus and a concomitant decrease of H3K4me3.

We then studied the effects of $\mathrm{Hb}$ overexpression in vivo. Two striking phenotypes were observed in the timeframe of the experiment (1 month). As in vitro, aggregates are present in the nucleus of $\mathrm{TH}^{+}$cells. In the large majority of cases, they contain both $\alpha$ - and $\beta$-chains. Most importantly, we observed a significant difference in motor behaviour between AAV9-Hb mice and AAV9-controls. To our knowledge, this is the first experimental evidence of behavioural effects of neuronal $\mathrm{Hb}$. As it is well known that changes in DA neurotransmission result in motor skill learning deficit ${ }^{23}$ and that we observed a reduction of DA content owing to $\mathrm{Hb}$ overexpression, we speculate that $\mathrm{Hb}$ may influence the physiological status of DA neurons leading to a dysregulation of DA neurotransmission. No changes in DA histology were found considering densitometric analysis of $\mathrm{TH}^{+}$fibres in the striatum and the number of total $\mathrm{TH}^{+}$neurons in $\mathrm{SN}$. Although genetic inhibition of rRNA biogenesis requires several months to trigger DA cells' degeneration, AAV9-Hb mice with motor skill learning deficit were analysed 1 month upon AAVs injection, opening the possibility that neuronal damage may become evident at later time.

Although our data prove that neuronal $\mathrm{Hb}$ regulates pathways involved in PD pathogenesis and potentially DA activity in vivo, its function remains unclear. By replacing the highly conserved proximal histidine F8 residue with a glycine, mutated $\mathrm{Hb}$ presents a low affinity for the heme group and $\mathrm{a}$ loss of its allosteric properties. ${ }^{15,16}$ In these conditions, we observed that mutated $\mathrm{Hb}$ confers susceptibility to neurotoxic stimuli as wild-type $\mathrm{Hb}$, suggesting that $\mathrm{Hb}$ toxicity does not depend on $\mathrm{O}_{2}$ binding. 
Overall, we hypothesize that neuronal $\mathrm{Hb}$ acts as a sensor of the energy status of neurons. By linking ATP concentration and mitochondrial function to mTOR activity, it may regulate cells' stress response acting on ribosome biogenesis, autophagy, the epigenome and, ultimately, DA cells' neurotransmission.

Although it is unclear how $\mathrm{Hb}$ expression is regulated in nonerythroid cells, A9 neurons present the expression of GATA family members ${ }^{12,49}$ that are the major $\mathrm{Hb}$ transcriptional regulators. In this context, any environmental or genetic conditions that modify $\mathrm{Hb}$ levels in A9 cells may affect neuronal susceptibility. Interestingly, $\mathrm{Hb}$ chains have been found highly induced by low iron diet in the ventral midbrain of adult mice, implicating them in brain iron homeostasis, a pathway involved in PD as well. ${ }^{50}$ On the other hand, it will be interesting to assess the relationship, if any, of $\mathrm{Hb}$ levels in blood and DA cells in normal and pathological conditions of hematological origin, such as thalassemia. Recent reports ${ }^{51,52}$ associate blood $\mathrm{Hb}$ levels and $\mathrm{PD}$, suggesting that high $\mathrm{Hb}$ is linked to an increase risk of PD.

Our results support a model where $\mathrm{Hb}$ levels in A9 neurons may be associated with cellular susceptibility in PD, positioning $\mathrm{Hb}$ in the list of potential PD modifiers that deserve further attention.

\section{Materials and Methods}

Generation of stable cell line. From pBudCE4.1- $\beta$-globin-MYC-IRESeGFP, 2xFLAG- $\alpha$-globin, as previously described, ${ }^{12}$ we generated a mutated mouse $\mathrm{Hb}$, that we called pBUD-mut $\beta$-globin-MYC-IRES-eGFP, 2xFLAG-mut $\alpha$-globin. In detail, the proximal hystidines of $\alpha$ - and $\beta$-chains were mutated into a glycine (respectively, His87Gly and His92Gly). We used the QuikChange Site-Directed Mutagenesis Kit (Stratagene, San Diego, CA, USA) according to the manufacturer's instructions. The list of primers used for mutagenesis is in Supplementary Table S1. iMN9D cell line was transfected with pBUD-mut $\beta$-globin-MYC-IRES-eGFP, 2xFLAG-mut $\alpha$-globin using Lipofectamine 2000 (Life Technologies, Carlsbad, CA, USA) according to the manufacturer's instructions. After $24 \mathrm{~h}$ of transfection, cells were collected. A cell strainer with $70 \mu \mathrm{m}$ nylon mesh (BD Falcon, Franklin Lakes, NJ, USA) was used to obtain a single-cell suspension before sorting. 7-AAD (Beckman-Coulter, Brea, CA, USA) was added to the cell suspension to exclude dead cells. A high-speed cell sorter (MoFlo, Brea, CA, USA) was used to sort subpopulation of cells expressing green fluorescent protein (GFP). Sorting parameters used were described previously. ${ }^{12}$ After sorting, cells were re-plated, and $48 \mathrm{~h}$ later, $300 \mu \mathrm{g} / \mathrm{ml}$ zeocyn (Life Technologies) was added for selection.

Cell cultures and treatments. We used MN9D-Nurr1 ${ }^{\text {Tet-on }}$ (iMN9D) cell line stably transfected with pBUD-IRES-eGFP (that we called control cells) or with pBUD- $\beta$-globin-MYC IRES-eGFP, 2xFLAG- $\alpha$-globin (that we called Hb cells), as previously described, ${ }^{12}$ or with pBUD-mut $\beta$-globin-MYC-IRES-eGFP, 2xFLAG-mut $\alpha$-globin (that we called mut $\mathrm{Hb}$ cells). Cells were maintained in culture using DMEM/F12 medium (Life Technologies) supplemented with $10 \%$ fetal bovine serum (Sigma-Aldrich, St. Louis, MO, USA), $100 \mu \mathrm{g} / \mathrm{ml}$ penicillin (Sigma-Aldrich), $100 \mu \mathrm{g} /$ $\mathrm{ml}$ streptomycin (Sigma-Aldrich), $300 \mu \mathrm{g} / \mathrm{ml}$ neomycin (Life Technologies) selection and $150 \mu \mathrm{g} / \mathrm{ml}$ zeocyn (Life Technologies) selection at $37^{\circ} \mathrm{C}$ in a humidified $\mathrm{CO}_{2}$ incubator. Nurr1 expression in iMN9D cell lines were induced by addition of $3 \mu \mathrm{g} / \mathrm{ml}$ doxycycline (Sigma-Aldrich) to the culture medium every $48 \mathrm{~h}$. Cells were grown as above except that the $10 \%$ fetal bovine serum was changed to $5 \%{ }^{53}$ For treatments, the following reagents were used: $\mathrm{MPP}^{+}$(Sigma-Aldrich) and rotenone (Sigma-Aldrich) for $16 \mathrm{~h}$ at different concentrations.

Generation and purification of recombinant AAVs. We used AAV serotype 9 for our experiments because of its high expression level and its brain tropism. ${ }^{54}$ The fragments corresponding to 2xFLAG- $\alpha$-globin and $\beta$-globin-MYC were cloned into the pAAV-MCS vector (Agilent Technologies, Santa Clara, CA, USA), which was used to produce recombinant AAV vectors. In addition, we use pAAV-MCS vector as control. AAV of serotype 9 were generated in HEK 293 T cells, using a triple-plasmid co-transfection for packaging. Viral stocks were obtained by $\mathrm{CsCl}_{2}$ gradient centrifugation. Titration of AAV viral particles was performed by realtime PCR quantification of the number of viral genomes. The viral preparations had the following titres: AAV9-2xFLAG- $\alpha$-globin $7 \times 10^{13}$ viral genome particles $/ \mathrm{ml}$, AAV9- $\beta$-globin-MYC $8.8 \times 10^{13}$ viral genome particles/ml and AAV9-control $7.5 \times 10^{12}$ viral genome particles $/ \mathrm{ml}$.

Animals. All animal experiments were performed in accordance with European guidelines for animal care and following Italian Board of Health permissions (DM 2/2012-B, 9 January 2012). Mice were housed and bred in SISSA animal facility, with $12 \mathrm{~h}$ dark/light cycles and controlled temperature and humidity. Food and water were provided ad libitum.

Rotarod test. To measure locomotor activity, mice were tested with a rotarod apparatus with automatic timers and falling sensors (Crisel Instruments, Roma, Italy) at the indicated number of weeks during the light phase of the $12 \mathrm{~h}$ light/12 $\mathrm{h}$ dark cycle. Mice were first trained on the rotarod for 5 consecutive days. Animals that stayed on the rod for $300 \mathrm{~s}$ at 5 r.p.m. during training were selected and were randomly assigned to two groups. Mice were tested for four trials (maximum of $300 \mathrm{~s} /$ trial) at 5, 10, 15 and 20 r.p.m. For each trial, the time each mouse remained on the rotating rod was recorded and the best three trials were averaged as a measure of motor performance.

Stereotaxic surgery. The stereotaxic procedure followed were according to Cetin et al. ${ }^{55}$ Adult (8 week old) male C57B//6 mice weighing $25 \mathrm{~g} \pm 3 \mathrm{~g}$ were used for experiments. Mice were preanaesthetized with Tramadolo i.p. (30 mg/kg body weight) and anaesthetized with a mixture of Xylazina (15 mg/kg body weight) and Zoletil (15 mg/kg body weight) i.p. A stereotaxic injection of $3 \mu \mathrm{l}$ of viral vector suspension (AAV9-control or a mixture of AAV9-2xFLAG- $\alpha$-globin and AAV9- $\beta$ globin-MYC, that we called AAV9-Hb) was delivered to the left SNpc. The coordinates were: anterior/posterior $(\mathrm{A} / \mathrm{P})-3.2 \mathrm{~mm}$ from bregma, medio/lateral $(\mathrm{M} / \mathrm{L})-1.2 \mathrm{~mm}$ from bregma and dorso/ventral $(\mathrm{D} / \mathrm{N})-4.5 \mathrm{~mm}$ from the dura. The coordinates used were calculated according to the Franklin and Paxinos Stereotaxic Mouse Atlas. The injection rate was $0.2 \mu \mathrm{l} / 30 \mathrm{~s}$ using a $10 \mu \mathrm{l}$ syringe with 26 gauge needle (SGE, Ringwood, VIC, Australia).

Tissue collection and processing. At the indicated number of weeks after injection of AAVs into SNpc, the animals were killed. Following induction of deep anaesthesia with an overdose of a mixture of Xylazina and Zoletil, the animals were intensively perfused transcardially with PBS $1 x$. For biochemical analysis, SN, striatum and CTX were dissected and immediately frozen in liquid nitrogen and stored at $-80^{\circ} \mathrm{C}$, pending analyses. For immunohistochemical analysis, after the intensively transcardially perfusion with PBS $1 x$, animals were perfused with $4 \%$ paraformaldehyde diluted in PBS $1 \times$. Brains were immediately dissected with the Mouse Brain Matrix instrument (Protech International Inc., San Antonio, TX, USA) and separated into two pieces, the anterior part containing the striatum and the posterior one containing SN. Brains were postfixed in $4 \%$ paraformaldehyde for $1 \mathrm{~h}$ at $4{ }^{\circ} \mathrm{C}$. The regions containing the striatum and $\mathrm{SN}$ were cut in $40 \mu \mathrm{m}$ free-floating slides with a vibratome (Vibratome Series 1000 Sectioning System, Technical Products International, St. Louis, MO, USA). Four consecutive series were collected in order to represent the whole area of interest.

PCR and quantitative RT-PCR (qRT-PCR). Total RNA was extracted from cell and mouse tissue samples using the TRIzol reagent (Life Technologies) following the manufacturer's instructions. Mouse tissues were homogenized using a glass-Teflon (Thermo Scientific, Waltham, MA, USA). A fraction of the total RNA samples were subjected to DNase I treatment (Life Technologies) at $37^{\circ} \mathrm{C}$ for $1 \mathrm{~h}$ and the sample was then purified on RNAeasy mini kit columns (Qiagen, Hilden, Germany). The final quality of RNA sample was tested on agarose gel. Singlestrand cDNA was obtained from $1 \mu \mathrm{g}$ of purified RNA using the iSCRIPT cDNA Synthesis Kit (Bio-Rad, Hercules, CA, USA) according to the manufacturer's instructions. To amplify transcripts, Ex Taq DNA polymerase (Takara Bio Inc., Kasatsu, Japan) was used. qRT-PCR was performed in triplicate using SYBERGreen PCR Master Mix (Bio-Rad) and an iCycler IQ Real Time PCR System (BioRad). Relative gene expression was calculated with $\Delta \Delta C$ t method. The complete list of primers used for PCR and RT-qPCR is in Supplementary Table S1. All amplicons were sequenced. 
Western blotting. Proteins derived from adherent and floating cells were collected, washed intensely with PBS $1 x$ and lysed in SDS sample buffer $2 x$. Proteins derived from mouse tissue were obtained using TRlzol reagent (Life Technologies) following the manufacturer's instructions. Proteins were separated in 10-17\% SDS polyacrylamide gel as needed. After the separation on gel, proteins were transferred to nitrocellulose membrane (GE Healthcare Life Science, Buckinghamshire, UK). Membrane was blocked with $5 \%$ nonfat milk in TBST solution (TBS and $0.1 \%$ Tween 20 ) and then incubated with primary antibodies overnight at $4{ }^{\circ} \mathrm{C}$ or at room temperature for $2 \mathrm{~h}$. The following antibodies were used: anti-Caspase-3 1:1000 (Cell Signaling, Danvers, MA, USA), anti-cleaved Caspase-3 1:1000 (Cell Signaling), anti-FLAG 1:2000 (Sigma-Aldrich), anti-MYC 1:2000 (Cell Signaling), anti- $\beta$-actin 1:10000 (Sigma-Aldrich), anti-TH 1:1000 (Sigma-Aldrich), anti-UBF 1:1000 (Santa Cruz, Dallas, TX, USA), anti-H3K4me3 1:5000 (Millipore, Billerica, MA, USA), anti-H3K9me2 1:5000 (Abcam, Cambridge, UK), anti-H3 1:10000 (Cell Signaling), anti- $\alpha$-tubulin 1:100 (purified from immunized rabbits), P-4E-BP1 1:1000 (Cell Signaling), 4E-BP1 1:1000 (Cell Signaling), antiLC3b 1:1000 (Cell Signaling), anti-Hemoglobin 1:1000 (MP Biomedicals, Santa Ana, CA, USA) and anti-GFP 1:1000 (Life Technologies). For development, secondary antibodies conjugated with horseradish peroxidase (Dako, Glostrup, Denmark) were used in combination with ECL reagent (GE Healthcare Life Science). Image acquisition was performed using the Alliance 4.7 software (UVITEC, Cambridge, UK). Quantification of protein bands from western blotting scans was performed with the ImageJ Software (National Institute of Health, Bethesda, MD, USA).

Coimmunoprecipitation. Cells were lysed in immunoprecipitation buffer (300 mM NaCl, 50 mM Tris pH 7.5, 1\% Nonidet P-40, 10\% glycerol), supplemented with protease inhibitor mixture (Roche Diagnostics, Basel, Switzerland) for $30 \mathrm{~min}$ at $4{ }^{\circ} \mathrm{C}$. Lysates were cleared at $15000 \times \mathrm{g}$ for $20 \mathrm{~min}$. Cell lysates were incubated with anti-FLAG agarose beads (Sigma-Aldrich). After washing, immunoprecipitated proteins were eluted with SDS sample buffer $2 x$, boiled and analyzed by western blotting.

Cellular fractionation. Nucleo-cytoplasmic separation was performed using the Nucleo-Cytoplasmic Separation Kit (Norgen Biotek Corp., Thorold, ON, Canada) according to the manufacturer's instruction. The effectiveness of cellular separation was controlled with cytoplasmic and nuclear markers $\mathrm{TH}$ and UBF, respectively.

Detergent-solubility fractionation. Detergent solubility was performed as previously described. ${ }^{56}$ In detail, cells were harvested in buffer containing $50 \mathrm{mM}$ Tris- $\mathrm{HCl} \mathrm{pH} 7.4,175 \mathrm{mM} \mathrm{NaCl}, 5 \mathrm{mM}$ EDTA pH 8.0 supplemented with protease inhibitor mixture (Roche Diagnostics). Cells were lysed once through a 30 gauge needle and sonicated for $10 \mathrm{~s}$. After the addition of Triton X-100 (final concentration $1 \%$ ), lysates were incubated for $30 \mathrm{~min}$ on ice and centrifugated at $15000 \times \mathrm{g}$ for $1 \mathrm{~h}$ at $4{ }^{\circ} \mathrm{C}$ in order to separate the Triton $\mathrm{X}-100$ soluble (supernatant) and insoluble (pellet) fractions. The pellet was dissolved in $2 \%$ SDS-containing lysis buffer and sonicated for $10 \mathrm{~s}$. The effectiveness of cellular separation was controlled with $\alpha$-tubulin, a marker of the soluble fraction.

Fluorescence-activated cell sorter analysis. For FACS analysis, both adherent and floating cells were collected and fixed in ice-cold $70 \%$ ethanol. After rehydration, cells were suspended in PBS $+0.1 \% \mathrm{NP} 40+200 \mu \mathrm{g} / \mathrm{ml}$ RNaseA and treated with $40 \mu \mathrm{g} / \mathrm{ml}$ propidium iodide and analyzed on a flow cytometer (FACSCalibur, BD Biosciences, Franklin Lakes, NJ, USA). At least $10^{4}$ GFP-positive cells were analysed in each acquisition. FACS data were processed using the FlowJo software (Tree Star Inc., Ashland, OR, USA) and cell cycle profiles were determined using the Watson pragmatic mode.

WST-1 analysis. Cell viability was assayed using WST-1 reagent (Roche Diagnostics), according to the manufacturer's protocol. In detail, absorbance was measured on a microplate ELISA reader (Thermo Scientific) at a 450 and $620 \mathrm{~nm}$ detection wavelength. Normalized WST was calculated as follows: WST $(\%)=\left(\left(A_{450 \mathrm{~nm}}-A_{620 \mathrm{~nm}}\right.\right.$ of treated sample $-A_{450 \mathrm{~nm}}-A_{620 \mathrm{~nm}}$ of blanck $) /\left(A_{450 \mathrm{~nm}}{ }^{-}\right.$ $A_{620 \mathrm{~nm}}$ of untreated sample $-A_{450 \mathrm{~nm}}-A_{620 \mathrm{~nm}}$ of blanck)) $\times 100$. Blank represents wells containing culture medium only.

Immunocytochemistry. Cells were fixed in $4 \%$ paraformaldehyde for $10 \mathrm{~min}$, then washed with PBS $1 \mathrm{x}$, treated with $0.1 \mathrm{M}$ glycine for $4 \mathrm{~min}$ in PBS $1 \mathrm{x}$ and permeabilized with $0.1 \%$ Triton X-100 in PBS $1 \times$ for 4 min. After washing with PBS $1 \times$ and blocking with $0.2 \%$ BSA, $1 \%$ NGS, $0.1 \%$ Triton X-100 in PBS $1 \times$, cells were incubated with primary antibodies diluted in blocking solution for $90 \mathrm{~min}$ at room temperature. After washes in PBS $1 x$, cells were incubated with labelled secondary antibodies for $60 \mathrm{~min}$. For nuclear staining, cells were incubated with $1 \mu \mathrm{g} / \mathrm{ml} \mathrm{DAPI}$ for $5 \mathrm{~min}$. Cells were washed and mounted with Vectashield mounting medium (Vector Laboratories, Burlingame, CA, USA). The following antibodies were used: anti-FLAG 1:1000 (Sigma-Aldrich), anti-MYC 1:2000 (Cell Signaling) and antiNPM 1:100 (Invitrogen, Carlsbad, CA, USA). For detection, Alexa Fluor-488, -594 or -405 (Life Technologies) antibodies were used. To detect insoluble $\mathrm{Hb}$, immunocytochemistry was performed as previously described. ${ }^{42}$ All images were collected using confocal microscopes (LEICA TCS SP2, Wetzlar, Germany and Nikon D-Eclipse C1, Tokyo, Japan). Using the Volocity 3D Image Analysis Software (PerkinElmer, Waltham, MA, USA), aggregates per cell were counted. Values were represented as percentage of the total.

LysoTracker staining. Cells were stained without fixation with $50 \mathrm{nM}$ LysoTracker Red (Molecular Probes, Eugene, OR, USA) in growth medium for $1 \mathrm{~h}$. Stained cells were immediately fixed with $4 \%$ paraformaldeide and follow a standard immunofluorescence protocol. LysoTracker staining were visualized with a confocal microscope (Nikon D-Eclipse C1). Using Volocity 3D Image Analysis Software (PerkinElmer), autophagosomes per cell were counted. Autophagy activity was defined as follows: ${ }^{57}$ high: >10 autophagosomes/cell; medium: 6-10 autophagosomes/cell; and low: $<6$ autophagosomes/cell. Values were represented as percentage of the total.

Immunohistochemistry. For immunohistochemistry, a standard avidin-biotin $A B C$ procedure was performed on free-floating slides. Endogenous peroxidase activity was first quenched by a 10 min incubation in 10\% methanol with $3 \%$ hydrogen peroxide in PBS $1 \times$, followed by incubation in 10\% NGS, $1 \%$ BSA and $1 \%$ Fish gelatin in PBS $1 \times$ for $1 \mathrm{~h}$. The primary and secondary antibodies were diluted in $1 \%$ BSA, $0.3 \%$ Triton X-100 and $0.1 \%$ Fish gelatin in PBS $1 \times$. Incubation with primary antibodies 1:1000 anti-TH (Sigma-Aldrich) was performed overnight at RT. Incubation with 1:200 biotinylated secondary antibody (Santa Cruz) was performed for $1 \mathrm{~h}$ at RT, followed by $1 \mathrm{~h}$ incubation in avidin-biotin-peroxidase solution (ABC Kit, Vector Laboratories). The staining was visualized using 3,3'diaminobenzidine (Sigma-Aldrich) as a chromogen for $2 \mathrm{~min}$. The sections were then mounted on slides (Thermo Scientific SuperFrost Plus), dehydrated in ascending alcohol concentrations, cleared in xylene and mounted with Eukitt mounting medium (O. Kindler $\mathrm{GmbH}$, Freiburg, Germany). All images were collected in bright-field (LEICA DM6000).

For fluorescent immunohistochemistry, free-floating slides were treated with $0.1 \mathrm{M}$ glycine for 5 min in PBS $1 \times$ and then with $1 \%$ SDS in PBS $1 \times$ for 1 min at RT. Slides were blocked with $10 \%$ NGS, $1 \%$ BSA and $1 \%$ Fish gelatin in PBS $1 \times$ for $1 \mathrm{~h}$ at RT. The antibodies were diluted in $1 \%$ BSA, $0.3 \%$ Triton $X-100$ and $0.1 \%$ Fish gelatin in PBS $1 \times$. For double immunoflurescence, incubation with primary antibodies was performed overnight at RT and incubation with 1:500 Alexa fluor-conjugated secondary antibodies (Life Technologie) was performed for $2 \mathrm{~h}$ at RT. Nuclei were labelled with $1 \mu \mathrm{g} / \mathrm{ml} \mathrm{DAPI}$. For triple immunofluorescence, incubation with primary antibodies was performed overnight at RT, incubation with 1:500 Alexa fluorconjugated secondary antibodies (Life Technologies) and 1:100 biotin-labelled secondary antibody (Sigma-Aldrich) was performed for $2 \mathrm{~h}$ at RT, followed by $1 \mathrm{~h}$ incubation in 1:100 streptavidin, Marina Blue conjugate (Life Technologies). Slides were mounted with mounting medium for fluorescence Vectashield (Vector Laboratories). The following primary antibodies were used: anti-TH 1:1000 (SigmaAldrich or Millipore), anti-FLAG 1:100 (Sigma-Aldrich), anti-MYC 1:100 (Cell Signaling) and anti-Hemoglobin 1:1000 (MP Biomedicals). For detection, Alexa fluor488 or -594 (Life Technologies) were used. All images were collected using confocal microscopes (LEICA TCS SP2).

Dopamine determination by HPLC. Cells were lysed in $200 \mu \mathrm{l}$ of $0.1 \mathrm{M}$ perchloric acid, sonicated and spun in a microcentrifuge at $10000 \times \mathrm{g}$ for $10 \mathrm{~min}$ at $4{ }^{\circ} \mathrm{C}$. The supernatant was transferred in ultra-free microcentrifuge tubes (Millipore) and spun at $10000 \times \mathrm{g}$ for $5 \mathrm{~min}$ at $4^{\circ} \mathrm{C}$. Samples $(11 \mu \mathrm{l})$ were injected into the HPLC apparatus. Measurements of dopamine were made by HPLC with an electrochemical detection system (ALEXYS LC-EC, Antec Leyden BV, Zoeterwoude, The Netherlands) equipped with a reverse-phase column (3- $\mu \mathrm{m}$ particles, ALB-215 C18, $1 \times 150 \mathrm{~mm}$, Antec Leyden BV) at a flow rate of $50 \mu \mathrm{l} / \mathrm{min}$ and electrochemically detected by a $0.7 \mathrm{~mm}$ glass carbon electrode (VT-03, Antec Leyden BV). The mobile phase contained $50 \mathrm{mM} \mathrm{H}_{3} \mathrm{PO}_{4}, 50 \mathrm{mM}$ citric acid, $8 \mathrm{mM}$ 
$\mathrm{KCl}, 0.1 \mathrm{mM}$ EDTA, $400 \mathrm{mg} / \mathrm{l}$ octanesulfonic acid sodium salt and $8 \%$ (vol/vol) acetonitrile $(\mathrm{pH} 3.0)$

Determination of striatal DA density. DA innervation in the striatum was estimated via optical density (OD) determination of immunostaining using Leica DM6000 microscope. Briefly, striatal sections were immunostained with anti-TH antibody. Scans of three different section were acquired corresponding to the rostral, intermediate and caudal portion of the striatum. Using the ImageJ Software (National Institute of Health), the region of interest on the section was outlined and the mean $\mathrm{OD}$ value for the region was determined. A background value, corresponding to a region devoid of immunoreactivity (i.e., corpus callosum), was subtracted from each determination. The OD values were calculated as arbitrary units and were expressed as a percentage relative to the contralateral side of control-injected mice.

Quantification of DA neurons in the SNpc. One out of the four series of $40 \mu \mathrm{m}$ freefloating slides were immunostained with anti-TH antibody. SNpc was outlined under a low magnification objective $(\times 4)$ following landmarks from the Franklin and Paxinos Mouse Atlas and was analyzed under a $\times 100$ objective of an Olympus BH2 microscope (Tokyo, Japan). Cells were counted throughout the whole SNpc area and through the entire section thickness. Quantification of $\mathrm{TH}^{+}$cells was performed according to a stereological approach using the Olympus CAST-Grid system (Olympus Denmark A/S, Albertslund, Denmark). $\mathrm{TH}^{+}$cells were counted by a systematically random sampling scheme using approximately $160 \times 160 \mu \mathrm{m}^{2}$ optical dissectors. All counts were performed blind to the experimental status of the animals. The orientation for each brain was determined by marking one side of each brain by performing an incision through the contralateral side of the brain. The $\mathrm{TH}^{+}$ cell values were expressed relative to the contralateral side of control-injected mice.

Statistical analysis. All data were obtained by at least three independent experiments. Data represent the mean \pm S.D.; each group was compared individually with the reference control group using Student's t-test (Microsoft Excel software, Microsoft, Redmond, WA, USA). Where appropriate, $P$-values were adjusted for multiple testing using the Benjamini-Hochberg procedure to control the false discovery rate. Statistical significance differences to reference samples were indicated. Regarding statistical analysis of in vivo experiments, data represent the mean \pm S.E.M. Each group and side differences were analysed by one-way ANOVA test using the STATVIEW software (Abacus Concepts, Berkeley, CA, USA). Significance was set at $P<0.05$.

\section{Conflict of Interest}

The authors declare no conflict of interest.

Acknowledgements. We are indebted to all the members of the SG lab for helping and thought-provoking discussions, especially M Maurutto, and to C Leonesi for technical support. We thank SISSA technicians, especially M Grandolfo, A Bisso (Laboratorio Nazionale CIB, Area Science Park, Trieste, Italy) for helping with FACS analysis and L Verga Falzacappa (University of Trieste, Trieste, Italy) for teaching stereotaxic surgery. This work was supported by grants from Ministero dell'Istruzione, dell'Università e della Ricerca (FIRB grant prot. RBAP11FRE9) to SG.

1. Dauer W, Przedborski S. Parkinson's disease: mechanisms and models. Neuron 2003; 39 : 889-909.

2. Chung $\mathrm{CY}$, Seo H, Sonntag KC, Brooks A, Lin L, Isacson O. Cell type-specific gene expression of midbrain dopaminergic neurons reveals molecules involved in their vulnerability and protection. Hum Mol Genet 2005; 14: 1709-1725.

3. Pan T, Kondo S, Le W, Jankovic J. The role of autophagy-lysosome pathway in neurodegeneration associated with Parkinson's disease. Brain J Neurol 2008; 131: 1969-1978.

4. Yitshak Sade M, Zlotnik Y, Kloog I, Novack V, Peretz C, Ifergane G. Parkinson's disease prevalence and proximity to agricultural cultivated fields. Parkinsons Dis 2015; 2015: 576564

5. Nicklas WJ, Youngster SK, Kindt MV, Heikkila RE. MPTP, MPP+ and mitochondrial function. Life Sci 1987; 40: 721-729.

6. Greenamyre JT, Sherer TB, Betarbet R, Panov AV. Complex I and Parkinson's disease. IUBMB Life 2001; 52: 135-141.

7. Höglinger GU, Carrard G, Michel PP, Medja F, Lombès A, Ruberg M et al. Dysfunction of mitochondrial complex I and the proteasome: interactions between two biochemical deficits in a cellular model of Parkinson's disease. J Neurochem 2003; 86: 1297-1307.

8. Pan T, Rawal P, Wu Y, Xie W, Jankovic J, Le W. Rapamycin protects against rotenoneinduced apoptosis through autophagy induction. Neuroscience 2009; 164: 541-551.

9. Tzeng YW, Lee LY, Chao PL, Lee HC, Wu RT, Lin AMY. Role of autophagy in protection afforded by hypoxic preconditioning against MPP+-induced neurotoxicity in SH-SY5Y cells. Free Radic Biol Med 2010; 49: 839-846.

10. Parlato $R$, Kreiner $G$. Nucleolar activity in neurodegenerative diseases: a missing piece of the puzzle? J Mol Med (Berl) 2013; 91: 541-547.

11. Rieker C, Engblom D, Kreiner G, Domanskyi A, Schober A, Stotz S et al. Nucleolar disruption in dopaminergic neurons leads to oxidative damage and parkinsonism through repression of mammalian target of rapamycin signaling. J Neurosci 2011; 31: 453-460.

12. Biagioli M, Pinto M, Cesselli D, Zaninello M, Lazarevic D, Roncaglia $P$ et al. Unexpected expression of alpha- and beta-globin in mesencephalic dopaminergic neurons and glial cells. Proc Natl Acad Sci USA 2009; 106: 15454-15459.

13. Richter F, Meurers BH, Zhu C, Medvedeva VP, Chesselet M-F. Neurons express hemoglobin alpha- and beta-chains in rat and human brains. J Comp Neurol 2009; 515 538-547.

14. Russo R, Zucchelli S, Codrich M, Marcuzzi F, Verde C, Gustincich S. Hemoglobin is present as a canonical $\alpha 2 \beta 2$ tetramer in dopaminergic neurons. Biochim Biophys Acta 2013; 1834: 1939-1943.

15. Barrick D. Replacement of the proximal ligand of sperm whale myoglobin with free imidazole in the mutant His-93-> Gly. Biochemistry (Mosc) 1994; 33: 6546-6554.

16. Barrick D, Ho NT, Simplaceanu V, Dahlquist FW, Ho C. A test of the role of the proximal histidines in the Perutz model for cooperativity in haemoglobin. Nat Struct Biol 1997; 4: 78-83.

17. Feng $Y$, Liu T, Dong S-Y, Guo Y-J, Jankovic J, Xu $\mathrm{H}$ et al. Rotenone affects $p 53$ transcriptional activity and apoptosis via targeting SIRT1 and H3K9 acetylation in SHSY5Y cells. J Neurochem 2015; 134: 668-676.

18. Calligaris R, Banica M, Roncaglia P, Robotti E, Finaurini S, Vlachouli $C$ et al. Blood transcriptomics of drug-naïve sporadic Parkinson's disease patients. BMC Genomics 2015; 16: 876.

19. Berger SL. The complex language of chromatin regulation during transcription. Nature 2007; 447: 407-412.

20. Ruthenburg AJ, Allis CD, Wysocka J. Methylation of lysine 4 on histone H3: intricacy of writing and reading a single epigenetic mark. Mol Cell 2007; 25: 15-30.

21. Chen S, Wang D-L, Liu Y, Zhao L, Sun F-L. RAD6 regulates the dosage of p53 by a combination of transcriptional and posttranscriptional mechanisms. Mol Cell Biol 2012; 32: 576-587.

22. Sarkar S. Regulation of autophagy by mTOR-dependent and mTOR-independent pathways: autophagy dysfunction in neurodegenerative diseases and therapeutic application of autophagy enhancers. Biochem Soc Trans 2013; 41: 1103-1130.

23. Shiotsuki H, Yoshimi K, Shimo Y, Funayama M, Takamatsu Y, lkeda K et al. A rotarod test for evaluation of motor skill learning. J Neurosci Methods 2010; 189: 180-185.

24. Ascenzi $\mathrm{P}$, Gustincich S, Marino M. Mammalian nerve globins in search of functions. IUBMB Life 2014; 66: 268-276.

25. Ono T, Cutler RG. Age-dependent relaxation of gene repression: increase of endogenous murine leukemia virus-related and globin-related RNA in brain and liver of mice. Proc Nat Acad Sci USA 1978; 75 : 4431-4435.

26. Schelshorn DW, Schneider A, Kuschinsky W, Weber D, Krüger C, Dittgen T et al. Expression of hemoglobin in rodent neurons. J Cereb Blood Flow Metab 2009; 29: 585-595.

27. Ohyagi Y, Yamada T, Goto I. Hemoglobin as a novel protein developmentally regulated in neurons. Brain Res 1994; 635: 323-327.

28. He Y, Hua Y, Lee J-Y, Liu W, Keep RF, Wang MM et al. Brain alpha- and beta-globin expression after intracerebral hemorrhage. Trans/ Stroke Res 2010; 1: 48-56.

29. Blalock EM, Chen K-C, Sharrow K, Herman JP, Porter NM, Foster TC et al. Gene microarrays in hippocampal aging: statistical profiling identifies novel processes correlated with cognitive impairment. J Neurosci 2003; 23: 3807-3819.

30. Chuang J-Y, Lee C-W, Shih Y-H, Yang T, Yu L, Kuo Y-M. Interactions between amyloid- $\beta$ and hemoglobin: implications for amyloid plaque formation in Alzheimer's disease. PloS One 2012; 7: e33120.

31. Lee C-W, Shih Y-H, Kuo Y-M. Cerebrovascular pathology and amyloid plaque formation in Alzheimer's disease. Curr Alzheimer Res 2014; 11: 4-10.

32. Mills JD, Kim WS, Halliday GM, Janitz M. Transcriptome analysis of grey and white matter cortical tissue in multiple system atrophy. Neurogenetics 2015; 16: 107-122.

33. Barbisin M, Vanni S, Schmädicke A-C, Montag J, Motzkus D, Opitz L et al. Gene expression profiling of brains from bovine spongiform encephalopathy (BSE)-infected cynomolgus macaques. BMC Genomics 2014; 15: 434.

34. Freed J, Chakrabarti L. Defining a role for hemoglobin in Parkinson's disease. $N p$ Parkinsons Dis 2016; 2: 16021.

35. Meurers BH, Zhu C, Fernagut PO, Richter F, Hsia YC, Fleming SM et al. Low dose rotenone treatment causes selective transcriptional activation of cell death related pathways in dopaminergic neurons in vivo. Neurobiol Dis 2009; 33: 182-192.

36. Vogt IR, Lees AJ, Evert BO, Klockgether T, Bonin M, Wüllner U. Transcriptional changes in multiple system atrophy and Parkinson's disease putamen. Exp Neurol 2006; 199: $465-478$. 
37. Yang W, Li X, Li X, Li X, Yu S. Neuronal hemoglobin in mitochondria is reduced by forming a complex with $\alpha$-synuclein in aging monkey brains. Oncotarget 2016; 7: 7441-7454.

38. Shephard F, Greville-Heygate O, Marsh O, Anderson S, Chakrabarti L. A mitochondria location for haemoglobins-dynamic distribution in ageing and Parkinson's disease. Mitochondrion 2014; 14: 64-72.

39. Shephard F, Greville-Heygate O, Liddell S, Emes R, Chakrabarti L. Analysis of mitochondrial haemoglobin in Parkinson's disease brain. Mitochondrion 2016; 29: 45-52.

40. Brown N, Alkhayer K, Clements R, Singhal N, Gregory R, Azzam S et al. Neuronal hemoglobin expression and its relevance to multiple sclerosis neuropathology. J Mol Neurosci 2016; 59: 1-17.

41. Lam YW, Trinkle-Mulcahy L. New insights into nucleolar structure and function. F1000prime Rep 2015; 7: 48.

42. Vilotti S, Codrich M, Dal Ferro M, Pinto M, Ferrer I, Collavin L et al. Parkinson's disease DJ-1 L166P alters rRNA biogenesis by exclusion of TTRAP from the nucleolus and sequestration into cytoplasmic aggregates via TRAF6. PLoS One 2012; 7: e35051.

43. Vilotti S, Biagioli M, Foti R, Dal Ferro M, Lavina ZS, Collavin L et al. The PML nuclear bodiesassociated protein TTRAP regulates ribosome biogenesis in nucleolar cavities upon proteasome inhibition. Cell Death Differ 2012; 19: 488-500.

44. Boulon S, Westman BJ, Hutten S, Boisvert F-M, Lamond Al. The nucleolus under stress. Mol Cell 2010; 40: 216-227.

45. Kreiner G, Bierhoff H, Armentano M, Rodriguez-Parkitna J, Sowodniok K, Naranjo JR et al. A neuroprotective phase precedes striatal degeneration upon nucleolar stress. Cell Death Differ 2013; 20: 1455-1464.

46. Lynch-Day MA, Mao K, Wang K, Zhao M, Klionsky DJ. The role of autophagy in Parkinson's disease. Cold Spring Harb Perspect Med 2012; 2: a009357.

47. Liu K, Shi N, Sun Y, Zhang T, Sun X. Therapeutic effects of rapamycin on MPTP-induced Parkinsonism in mice. Neurochem Res 2013; 38: 201-207.

48. Wiley: Discriminant Analysis and Statistical Pattern Recognition - Geoffrey McLachlan http://eu.wiley.com/WileyCDAWileyTitle/productCd-0471691151.html. Accessed 4 April 2016.

49. Scherzer CR, Grass JA, Liao Z, Pepivani I, Zheng B, Eklund AC et al. GATA transcription factors directly regulate the Parkinson's disease-linked gene alpha-synuclein. Proc Natl Acad Sci USA 2008; 105: 10907-10912.
50. Jellen LC, Lu L, Wang X, Unger EL, Earley CJ, Allen RP et al. Iron deficiency alters expression of dopamine-related genes in the ventral midbrain in mice. Neuroscience 2013; 252: 13-23.

51. Savica R, Grossardt BR, Carlin JM, Icen M, Bower JH, Ahlskog JE et al. Anemia or low hemoglobin levels preceding Parkinson disease: a case-control study. Neurology 2009; 73: 1381-1387.

52. Abbott RD, Ross GW, Tanner CM, Andersen JK, Masaki KH, Rodriguez BL et al. Late-life hemoglobin and the incidence of Parkinson's disease. Neurobiol Aging 2012; 33: 914-920.

53. Hermanson $E$, Joseph $B$, Castro $D$, Lindqvist $E$, Aarnisalo $P$, Wallén $A$ et al. Nurr1 regulates dopamine synthesis and storage in MN9D dopamine cells. Exp Cell Res 2003; 288: 324-334.

54. Zincarelli C, Soltys S, Rengo G, Rabinowitz JE. Analysis of AAV serotypes 1-9 mediated gene expression and tropism in mice after systemic injection. Mol Ther 2008; 16: 1073-1080.

55. Cetin A, Komai S, Eliava M, Seeburg PH, Osten P. Stereotaxic gene delivery in the rodent brain. Nat Protoc 2006; 1: 3166-3173.

56. Klucken J, Shin Y, Masliah E, Hyman BT, McLean PJ. Hsp70 reduces alpha-synuclein aggregation and toxicity. J Biol Chem 2004; 279: 25497-25502.

57. Wu H, Wang MC, Bohmann D. JNK protects Drosophila from oxidative stress by trancriptionally activating autophagy. Mech Dev 2009; 126: 624-637.

(i) Cell Death and Disease is an open-access journal published by Nature Publishing Group. This work is licensed under a Creative Commons Attribution 4.0 International License. The images or other third party material in this article are included in the article's Creative Commons license, unless indicated otherwise in the credit line; if the material is not included under the Creative Commons license, users will need to obtain permission from the license holder to reproduce the material. To view a copy of this license, visit http://creativecommons.org/licenses/by/4.0/

(C) The Author(s) 2017

Supplementary Information accompanies this paper on Cell Death and Disease website (http://www.nature.com/cddis) 